\title{
Differences in the fatty acid composition of larvae and metamorphosing sea lampreys, Petromyzon marinus
}

\author{
Yung-Hsi Kao ${ }^{\mathrm{a}, *}$, John H. Youson ${ }^{\mathrm{b}}$, Brady Vick ${ }^{\mathrm{c}}$, Mark A. Sheridan ${ }^{\mathrm{d}}$ \\ ${ }^{a}$ Department of Life Science, College of Science, National Central University, Chung-Li City, Taoyuan 32054, Taiwan, ROC \\ ${ }^{\mathrm{b}}$ Department of Zoology and Division of Life Sciences, Scarborough Campus, University of Toronto, Scarborough, Ontario, \\ Canada M1C $1 A 4$ \\ ${ }^{\mathrm{c}}$ US Department of Agriculture, Agricultural Research Service, Northern Crop Science Laboratory, Fargo, ND 58105-5677, USA \\ ${ }^{\mathrm{d} D e p a r t m e n t}$ of Zoology and Regulatory Bioscience Center, North Dakota State University, Fargo, ND 58105-5517, USA
}

Received 28 May 2001; received in revised form 12 September 2001; accepted 8 October 2001

\begin{abstract}
This study was designed to evaluate biochemical changes in the fatty acid (FA) compositions of selected lipid depot (kidney and liver) and absorption (intestine) organs in larvae and metamorphosing sea lamprey, Petromyzon marinus. Palmitic or stearic acids were generally the predominant saturated fatty acids (SFA) before and during metamorphosis, but the greatest proportion of myristic acid occurred in renal triacylglycerol (TG). Monoenes, dienes, and polyenes

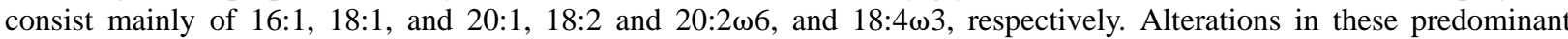
fatty acids occurred during lamprey metamorphosis, but depended on tissue, lipid class, and developmental status. During metamorphosis, kidney TG and phospholipid (PL) classes tended to mobilize SFA and enhance the fatty acid unsaturation, as indicated by increased unsaturated/saturated ratio, unsaturation index (USI), and total mean chain length (MCL). There was a tendency to increase saturation in the fatty acids of liver TG and PL classes and intestine TG, FA and monoacylglycerol (MG) classes, but to increase unsaturation in the fatty acids of liver cholesteryl ester (CE), FA and MG classes and intestine PL and CE classes from larva or stage 3 to stage 7. Increased polyunsaturated fatty acids in kidney TG and PL from larvae to stage 5 transformers and intestine PL and CE from stage 3 to stage 7 transformers may reflect an osmoregulatory pre-adaptation. The presence of branched-chain SFA (BCSFA) and the odd number of fatty acids (ONFA) indicated a significant role of detritivores in the benthic larvae. Decreased abundance of BCSFA, ONFA, and 18:2 dienes occurred in the transformed intestine TG as non-trophic metamorphosis proceeded. These data suggest that sea lamprey metamorphosis may proceed in a habitat, dietary, osmoregulatory, energetic, and developmental pre-adaptation of fatty acid composition from benthic filter-feeding larvae to pelagic parasitic juveniles. (C) 2002 Elsevier Science Inc. All rights reserved.
\end{abstract}

Keywords: Fatty acid; Monoacylglycerol; Diacylglycerol; Triacylglycerol; Phospholipid; Cholesteryl ester; Unsaturation index; Lamprey; Petromyzon marinus; Metamorphosis

\section{Introduction}

The development of sea lamprey, Petromyzon marinus, includes a seven-stage metamorphosis (Potter et al., 1978; Youson and Potter, 1979)

* Corresponding author. Tel.: +886-3-426-0839; fax: + 886-3-422-8482.

E-mail address: ykao@cc.ncu.edu.tw (Y.-H. Kao). which transforms microphagic filter-feeding larvae into pelagic parasitic juveniles, which live in either freshwater (landlocked) or seawater (anadromous form) (Hardisty, 1979). The metamorphosing larvae exhibit morphological, physiological and biochemical adaptations (Youson, 1980) before entry into the lake or the ocean (Beamish, 1980). Since 
metamorphosis in $P$. marinus is non-trophic, an important preparatory step for this development episode is the accumulation of energy reserves sufficient for basal metabolism and fuel tissue rearrangements. The pronounced lipid accumulation in specific organs of pre-metamorphic larvae and the subsequent marked lipid mobilization from the whole body (Lowe et al., 1973) and lipid depot sites (O'Boyle and Beamish, 1977; Youson et al., 1979; Kao et al., 1997a) have been observed. Histological and biochemical evidence indicated that sea lampreys, like other poikilotherms (Sheridan, 1994), use a diverse strategy of lipid metabolism before and during their metamorphosis by storing lipids among several depots, including liver, kidney, fat column, subcutaneous tissue and myosepta (Lowe et al., 1973; O'Boyle and Beamish, 1977; Youson et al., 1979; Kao et al., 1997a).

A detailed examination of tissue lipid class composition during metamorphosis of $P$. marinus by Kao et al. (1997a) indicated that sea lamprey metamorphosis proceeded in two distinct metabolic phases. The first phase, displayed between larvae and stage $3 / 4$ of metamorphosis, was predominated by lipid accumulation in kidney and liver and by lipid depletion from intestine. The second phase, displayed between stage $3 / 4$ and stage 7 , was characterized by lipid mobilization from kidney and liver and by lipid accretion to intestine. Such a two-phase pattern of tissue lipid alterations during metamorphosis of $P$. marinus was reflected by a two-phase pattern of changes in condition factor (an important criterion determining the incidence of lamprey metamorphosis; Youson et al., 1993) and primarily resulted from specific anabolism and catabolism of stored triacylglycerol lipid reserves, although other lipid classes, e.g. cholesterol (C) and phospholipid (PL), were also observed to change (Kao et al., 1997a,b).

In teleost fish, fatty acid composition has been suggested to reflect osmoregulatory pre-adaptation (Sheridan et al., 1985), dietary source, nutritional status, lipid utilization, fatty acid metabolism, and, perhaps, other environmental (e.g. thermal) and physiological (e.g. hormonal) cues (Henderson and Tocher, 1987; Hoch, 1988). Changes in fatty acid compositions from the plasma, whole body, and/or tissues (e.g. liver, gonad, muscle) have been reported in several species of lampreys, including one non-parasitic lamprey, L. planeri (Bird et al., 1993), two anadromous parasitic southern-hemisphere lampreys, M. mordax (Fel- lows and Mclean, 1982) and G. australis (Bird and Potter, 1983), two anadromous parasitic northern-hemisphere lampreys, L. tridentata (Whyte et al., 1993) and L. fluviatilis (Bird et al., 1993), and one landlocked parasitic northern-hemisphere sea lamprey, P. marinus (LeBlanc et al., 1995). These investigations, however, focused only on pre-metamorphic larvae, downstream migrants, upstream migrants, and adult lampreys. Whether changes in lamprey fatty acid composition are associated with their metamorphosis is not known. In addition, there is still no information regarding the fatty acid composition of larval sea lamprey, P. marinus. Accordingly, landlocked lamprey, $P$. marinus, was used in this study to evaluate changes in fatty acid composition during lamprey metamorphosis.

\section{Materials and methods}

\subsection{Animals}

Larvae and transformers at different stages (stages 3, 5 and 7) of metamorphosis were collected as described by Kao et al. (1997a). Stages 3,5 and 7 were chosen since they, respectively, represented early, middle and late stages of metamorphosis (Youson and Potter, 1979). Larvae were taken from the Chippewa River near Rogers City, Michigan, in late May of 1991 and transported to the Hammond Bay Biological Station at Millersburg, Michigan, where they were fed with baker's yeast once a week, maintained at a temperature of $21{ }^{\circ} \mathrm{C}$ in continuously flowing water and a photoperiod of $15 \mathrm{~h}$ light and $9 \mathrm{~h}$ dark, and provided with sand for burrowing. Under these conditions, some of the larvae underwent spontaneous metamorphosis and the transforming larvae, which are spontaneously non-trophic (Potter et al., 1978; Youson and Potter, 1979), were staged (3-7) according to the criteria of Youson and Potter (1979). Such criteria were based on the following significant external morphological changes: (1) the appearance and shape of eyes (Stages 1-3); (2) the structure of the oral aperture (Stages 2-4); (3) the degree of development of the tongue-like piston (Stages 4-7); (5) the shape and degree of cornification of the teeth (Stages 4-7); and (7) the coloration of the body (Stages 5-7). For example, the respective key characters of Stage 3, Stage 5 and Stage 7 transforming larvae include the first clear differentiation of eye with a dark inner pupil and a lighter outer iris, the visible 
precursors of teeth on oral disc and rudimentary fimbriae around its edges, and whitish yellow teeth of oral disc and fine serrated edges of lingual laminae. Animals were anesthetized with buffered MS222 and tissues (liver, kidney, and intestine) were removed, frozen in liquid $\mathrm{N}_{2}$, and then stored at $-70{ }^{\circ} \mathrm{C}$ for later lipid class identification and fatty acid composition analysis.

\subsection{Fatty acid composition analysis}

As described by Kao et al. (1997a), tissue lipids were extracted and tissue lipid classes were separated by preparative thin-layer chromatography (TLC; Kieselgel $60 \mathrm{C}$, Merck) using the twosolvent system of Freeman and West (1966) and identified according to the commercial standards of cholesterol, cholesteryl oleate, oleic acid, monoolein, diolein, and triolein obtained from Sigma after visualization with $50 \%$ sulfuric acid. For fatty acid (FA) analysis, the FA-containing lipid classes were visualized with $0.05 \%(\mathrm{w} / \mathrm{v}$ in $100 \%$ ethanol) 2,7-dichlorofluorescein (Eastman Kodak Co.) under UV and were individually scraped off plates into the screw-capped glass tubes. Bands of silica gel containing cholesteryl ester, monoacylglycerol, diacylglycerol, triacylglycerol, and fatty acid classes were eluted in chloroform $\left(\mathrm{CHCl}_{3}\right)$ : methanol $(\mathrm{MeOH}), 2: 1(\mathrm{v} / \mathrm{v})$. Phospholipid bands were similarly removed from TLC plates, but eluted with $\mathrm{CHCl}_{3}: \mathrm{MeOH}, 1: 2$ (v/v). Fatty acid methyl esters (FAME) were prepared by transesterification with methanol-boron trifluoride (14\% boron trifluoride in $\mathrm{MeOH}$; Sigma) as described by Morrison and Smith (1964) and analyzed by gas chromatography (GC; Hewlett Packard Series 5970 A with automatic injection system).

The operation conditions for GC were as follows: column (DB-23, J\&W Scientific Inc.) length, $30 \mathrm{~m} \times 0.25 \mathrm{~mm}$ i.d.; column oven, 190$320{ }^{\circ} \mathrm{C}$, injection port, $230{ }^{\circ} \mathrm{C}$; flame ionization detector, $300{ }^{\circ} \mathrm{C}$; carrier gas, He; pressure, $25 \mathrm{psi}$; flow rate, $1.5 \mathrm{ml} / \mathrm{min}$. Fatty acid methyl esters were identified by GC-mass spectrometry (GC$\mathrm{MS})$ and by comparing retention times with commercial standards (obtained from Sigma and Nu-Chek Prep Inc.) and secondary standard, cod liver oil (cf. Ackman and Burgher, 1964). For identification of branched-chain saturated fatty acids, FAME were further prepared into pyrrolidide derivatives by the method of Andersson and Holman (1974) and identified by GC-MS. The amounts of each fatty acid composition are represented by the mole percentage. Polyunsaturated fatty acids (PUFA) represented the dienoic, trienoic, tetraenoic, pentaenoic, and hexaenoic fatty acids. Unsaturation index (USI) and mean chain length (MCL) were calculated as previously described by LeBlanc et al. (1995).

\subsection{Statistical analysis}

Data were expressed as means \pm S.E.M. Analysis of variance (ANOVA) and Duncan's multiple range test were used to examine differences among the various means; a probability level of 0.05 was used to indicate significance in comparison of means. All statistics were performed using SigmaStat (Jandel Scientific, Palo Alto, CA).

\section{Results}

\subsection{Triacylglycerol (TG) fatty acid composition}

Changes in fatty acid composition in the TG fraction of the kidney, liver, and intestine accompanied lamprey metamorphosis (Table 1). Several isomers could be present either in the saturated fatty acids (SFA), due to the branched methyl group position, including iso $(i)$ - and normal $(n)$ 14:0, $-16: 0$ and $-18: 0$, and $i-, n$-, and anteiso- $(a)$ $15: 0$ and $-17: 0$, or in the unsaturated fatty acids (USFA), due to differences in double bond position, including 16:1, 17:1, 18:1, 18:2, 18:3, 20:1, 20:3, 22:3, 22:4 and 22:5.

In the kidney, 14:0, 16:0 and 16:1 were the predominant (over 10\%) fatty acids at each stage; of these, the abundance of 16:0 changed significantly during lamprey metamorphosis (Table 1). The abundance of 12:0 also decreased from larva to stage 5. The abundance of straight-chain SFA (SCSFA, 58.6-63.2\%; particularly 12:0 and 16:0) and branched-chain SFA (BCSFA; Fig. 1b) tended to decrease during metamorphosis (Fig. 1a). A slight rise in the USFA/SFA ratio ranged from $0.46 \pm 0.02$ in larvae to $0.54 \pm 0.04$ at stage 7 . Monoenes (ME), composed primarily of 16:1 and 18:1, did not vary substantially during metamorphosis (Fig. 1c). Dienes (DE), comprised primarily of 18:2, displayed significant differences between larva and stage 3 (Fig. 1d). Polyunsaturated fatty acids (PUFA), consisting primarily of $18: 3$ and 18:4 and minute amounts of 20:5 $21: 5 \omega 2,22: 5 \omega 3$, and $22: 6 \omega 3$, displayed significant 
Table 1

Fatty acid composition (mol.\%) of triacylglycerol in the liver, kidney and intestine of lamprey, P. marinus, during metamorphosis ${ }^{\mathrm{a}}$

\begin{tabular}{|c|c|c|c|c|c|c|c|c|c|c|c|c|}
\hline \multirow{2}{*}{$\begin{array}{l}\text { Fatty } \\
\text { acids }\end{array}$} & \multicolumn{4}{|l|}{ Liver } & \multicolumn{4}{|c|}{ Kidney } & \multicolumn{4}{|l|}{ Intestine } \\
\hline & $\mathrm{L}$ & 3 & 5 & 7 & $\mathrm{~L}$ & 3 & 5 & 7 & $\mathrm{~L}$ & 3 & 5 & 7 \\
\hline $12: 0$ & 0.2 & $\operatorname{tr}$ & $\operatorname{tr}$ & 3.5 & $7.6^{*}$ & $4.6^{* *}$ & $3.5 * *$ & $4.3 * *$ & n.d. & n.d. & n.d. & $\operatorname{tr}$ \\
\hline 13:0 & n.d. & 0.2 & 0.1 & 0.1 & 0.2 & 1.2 & 1.1 & 1.4 & n.d. & n.d. & n.d. & 0.2 \\
\hline$n-14: 0^{\mathrm{b}}$ & $0.7 *$ & $4.7 *$ & $4.5^{*}$ & $3.9 *$ & $31.5^{*}$ & $30.3 *$ & $29.1 *$ & $28.8^{*}$ & $2.9^{*}$ & $2.0^{*}$ & $6.1^{* *}$ & $9.3 * *$ \\
\hline$n-15: 0^{\mathrm{b}}$ & $1.9^{*}$ & $3.7 * *$ & $4.3^{* *}$ & $4.3^{* *}$ & $6.4^{*}$ & $5.4^{*}$ & $5.2 *$ & $6.1^{*}$ & $3.9 *$ & $2.8^{*}$ & $4.8^{*}$ & $4.6^{*}$ \\
\hline$n-16: 0^{\mathrm{b}}$ & $17.6^{*}$ & $22.8^{*}$ & $25.3^{*}$ & $22.9^{*}$ & $14.2^{*}$ & $17.7 * *$ & $18.3^{* *}$ & $14.8^{*}$ & $15.4^{*}$ & $30.0 * *$ & $32.9 * *$ & $29.8^{* *}$ \\
\hline$n-17: 0^{\mathrm{b}}$ & $8.5^{*}$ & $7.2^{*}$ & $7.5^{*}$ & $3.6^{* *}$ & $3.5^{*}$ & $4.1^{*}$ & $3.8^{*}$ & $4.0^{*}$ & $10.0^{*}$ & $6.3 * *$ & $6.1 * *$ & $5.3^{* *}$ \\
\hline$n-18: 0^{\mathrm{b}}$ & $10.8^{*}$ & $8.5^{*}$ & $9.4^{*}$ & $11.1^{*}$ & $2.2^{*}$ & $2.8^{*}$ & $2.8^{*}$ & $2.6^{*}$ & $10.5^{*, * *}$ & $11.3^{*}$ & $7.8 * *$ & $8.0 * *$ \\
\hline $19: 0$ & $2.9 *$ & $1.6^{* *}$ & $1.6^{* *}$ & $1.6^{* *}$ & $0.8^{*}$ & $1.7 * *$ & $1.4 * *$ & $1.6^{* *}$ & $3.3 *$ & $3.9 *$ & $2.3^{*}$ & $2.3 *$ \\
\hline $20: 0$ & $2.7 *$ & $0.3^{* *}$ & $0.4 * *$ & $0.7 * *$ & $0.3^{*}$ & $0.2 * *$ & $0.2 * *$ & $0.3^{*}$ & $2.0^{*}$ & $1.6^{*}$ & $0.7 * *$ & $0.5^{* *}$ \\
\hline 21:0 & 1.0 & 0.9 & 0.7 & 1.0 & $\operatorname{tr}$ & $0.4^{*}$ & $0.3 *$ & $0.3^{*}$ & $1.2^{*}$ & $1.5^{* *}$ & $0.9^{*}$ & $0.8^{*}$ \\
\hline $22: 0$ & 1.1 & 1.9 & 1.0 & 1.4 & $\operatorname{tr}$ & $1.1^{*}$ & $0.8^{*}$ & $0.7 *$ & $1.0^{*}$ & $5.2 * *$ & $2.7 \dagger$ & $1.7 \ddagger$ \\
\hline $24: 0$ & 0.8 & 1.1 & 1.1 & 1.9 & n.d. & $0.2^{*}$ & $0.3^{*}$ & $0.2^{*}$ & $0.8^{*}$ & $3.4 * *$ & $1.7 \dagger$ & $1.4 \dagger$ \\
\hline $12: 1 \omega 1$ & 0.2 & 0.2 & 0.2 & 0.3 & 0.2 & 0.1 & 0.1 & 0.1 & n.d. & n.d. & n.d. & n.d. \\
\hline $13: 1 \omega 1$ & n.d. & 0.1 & $\operatorname{tr}$ & 0.1 & n.d. & n.d. & n.d. & n.d. & n.d. & n.d. & n.d. & n.d. \\
\hline $14: 1 \omega 5$ & n.d. & 0.2 & 0.1 & 0.2 & 1.2 & 0.9 & 1.2 & 1.2 & n.d. & n.d. & n.d. & 0.1 \\
\hline $15: 1 \omega 5$ & n.d. & 0.3 & 0.4 & 0.5 & 0.5 & 0.4 & 0.4 & 0.5 & n.d. & 0.2 & tr & 0.2 \\
\hline $16: 1 \omega 7^{b}$ & $3.5^{*}$ & $4.0^{*}$ & $3.9^{*}$ & $3.1^{*}$ & $15.3^{*}$ & $10.2^{*}$ & $12.9^{*}$ & $13.9^{*}$ & $5.5^{* * * *}$ & $3.8^{*}$ & $6.3 * * \dagger$ & $7.1 \dagger$ \\
\hline $17: 1 \omega 9^{b}$ & 0.4 & 0.8 & 0.6 & 0.3 & 1.5 & 1.2 & 1.3 & 1.4 & 0.8 & n.d. & 1.0 & n.d. \\
\hline $18: 1 \omega 9^{b}$ & $9.1^{*}$ & $8.0^{*}$ & $6.9^{*}$ & $7.7^{*}$ & $6.8^{*}$ & $4.4^{*}$ & $5.7^{*}$ & $5.6^{*}$ & $10.0 \dagger$ & $5.3^{*}$ & $6.2^{* * * *}$ & $7.5^{* *+}$ \\
\hline $20: 1 \omega 9^{b}$ & $3.6^{*}$ & $5.3^{*}$ & $4.2^{*}$ & $5.1 *$ & $0.3^{*}$ & $0.5^{* *}$ & $0.3^{*}$ & $0.5^{* *}$ & $3.5^{*}$ & $2.2 *$ & $1.7^{*}$ & $1.6^{*}$ \\
\hline $22: 1 \omega 9$ & 0.2 & 0.2 & 0.8 & 0.8 & $0.1^{*}$ & $0.3^{*}$ & $0.3^{*}$ & $0.2 *$ & $0.3^{*}$ & $0.9 *$ & $0.5^{*}$ & $0.6^{*}$ \\
\hline $24: 1 \omega 9$ & n.d. & n.d. & n.d. & n.d. & n.d. & n.d. & n.d. & n.d. & n.d. & n.d. & n.d. & 0.1 \\
\hline $18: 2 \omega 6^{b}$ & $6.1^{*}$ & $4.4^{*}$ & $5.2^{*}$ & $5.0^{*}$ & $2.2^{*}$ & $6.5^{* *}$ & $5.8 * *$ & $6.3^{* *}$ & $6.3^{*}$ & $5.0^{*}$ & $6.3^{*}$ & $4.2 *$ \\
\hline $19: 2 \omega 6$ & n.d. & 0.1 & 0.3 & 0.2 & $\operatorname{tr}$ & 0.1 & 0.1 & 0.1 & n.d. & n.d. & 0.2 & 0.2 \\
\hline $20: 2 \omega 6$ & $3.0^{*}$ & $0.8^{* *}$ & $0.8^{* *}$ & $0.9 * *$ & $0.2^{*}$ & $0.4 * *$ & $0.4^{* *}$ & $0.4 * *$ & $3.6^{*}$ & $1.1^{* *}$ & $1.0 * *$ & $1.2 * *$ \\
\hline $22: 2 \omega 6$ & 3.1 & 1.2 & n.d. & 1.1 & n.d. & n.d. & n.d. & n.d. & 1.7 & n.d. & n.d. & n.d. \\
\hline $18: 3 \omega 3^{c}$ & $3.3^{*}$ & $1.9^{* *}$ & $1.9 * *$ & $1.8^{* *}$ & $0.8^{*}$ & $2.0^{* *}$ & $1.6^{* *}$ & $1.8^{* *}$ & $3.3^{*}$ & $1.6^{* *}$ & $1.6^{* *}$ & $1.4^{* *}$ \\
\hline $20: \omega 3$ & 1.4 & 1.6 & 1.5 & 1.7 & 0.3 & 0.7 & 0.5 & 0.5 & 2.7 & 1.4 & 1.2 & 1.6 \\
\hline $22: 3 \omega 3^{b}$ & 0.4 & 1.1 & 0.8 & 1.6 & $\operatorname{tr}$ & n.d. & 0.3 & $\operatorname{tr}$ & 0.5 & 0.4 & 0.5 & 0.8 \\
\hline $18: 4 \omega 3$ & 6.2 & 7.4 & 7.7 & 7.8 & $1.0^{*}$ & $1.3^{*}$ & $1.2^{*}$ & $1.5^{*}$ & $4.7 *$ & $3.2 *$ & $3.4^{*}$ & $3.9 *$ \\
\hline $20: 4 \omega 3$ & 3.5 & 5.1 & 4.8 & 5.3 & 0.3 & 0.3 & 0.2 & 0.3 & 2.3 & 0.3 & 0.4 & 1.1 \\
\hline $22: 4 \omega 6$ & 2.2 & n.d. & n.d. & n.d. & n.d. & n.d. & n.d. & n.d. & $1.3^{*}$ & n.d. & n.d. & $0.2 * *$ \\
\hline $20: 5 \omega 3$ & n.d. & n.d. & n.d. & n.d. & 0.2 & 0.2 & 0.2 & 0.1 & n.d. & n.d. & 0.1 & 0.3 \\
\hline $21: 5 \omega 2$ & n.d. & n.d. & n.d. & n.d. & $\operatorname{tr}$ & 0.2 & 0.2 & 0.1 & n.d. & 5.1 & 2.4 & 1.1 \\
\hline $22: 5 \omega 3^{\mathrm{b}}$ & 0.9 & 3.3 & 3.1 & 2.3 & $0.3^{*}$ & $0.1^{*}$ & $0.2^{*}$ & $0.1^{*}$ & $0.7^{*}$ & n.d. & $0.3^{*}$ & $0.7^{*}$ \\
\hline $22: 6 \omega 3$ & $2.8^{*}$ & $0.5^{* *}$ & $0.7 * *$ & $1.1 * *$ & $0.3^{*}$ & $0.3^{*}$ & $0.2^{*}$ & $0.2^{*}$ & $1.9^{*}$ & $1.2 * *$ & $0.6 \dagger$ & $0.4 \dagger$ \\
\hline
\end{tabular}

${ }^{a}$ Data are expressed as means of determinations made on three pooled samples; three lamprey per pool. S.E.M.s are omitted for clarity. For each fatty acid, groups with different symbol designations $(*, * *, \dagger$ and $\$)$ for a particular tissue are significantly different $(P<0.05)$. n.d., not detectable; tr, trace amounts $(<0.1 \%)$; L, larva; 3, stage 3; 5, stage 5; 7 , stage 7 .

${ }^{\mathrm{b}}$ Isomers may be present; the predominant one is represented here but value is the summation of these isomers. For example, 14:0 fatty acid comprises iso-, normal-, and anteiso-14:0 and, etc. Those isomers in the unsaturated fatty acid compositions can be attributed

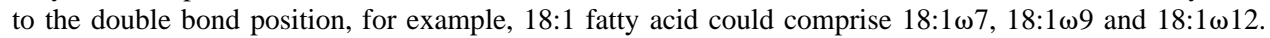

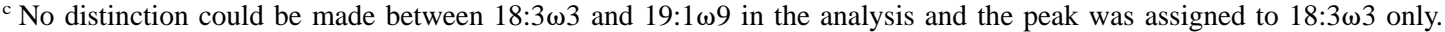

differences between larva and stage 3 (Fig. 2a) due to changes in the abundance of $\omega 3$ (e.g.

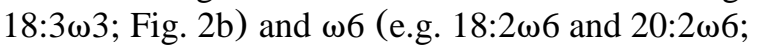
Fig. 2c) family FA. These alterations resulted in a trend toward increased unsaturation index (USI; Fig. 3b). Total odd number fatty acids (ONFA) and mean chain length (MCL) also increased during lamprey metamorphosis (Fig. 3).

The fatty acid composition of the hepatic TG class was quite distinct from that of the kidney (Table 1). The predominant FA were 16:0 and 18:0, although the abundance of neither of these 


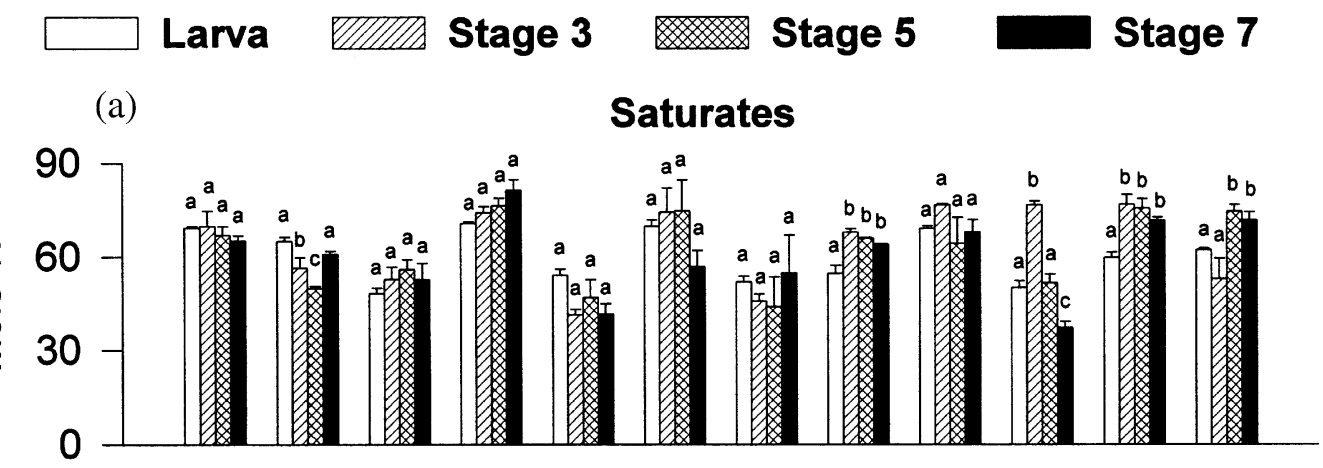

(b)
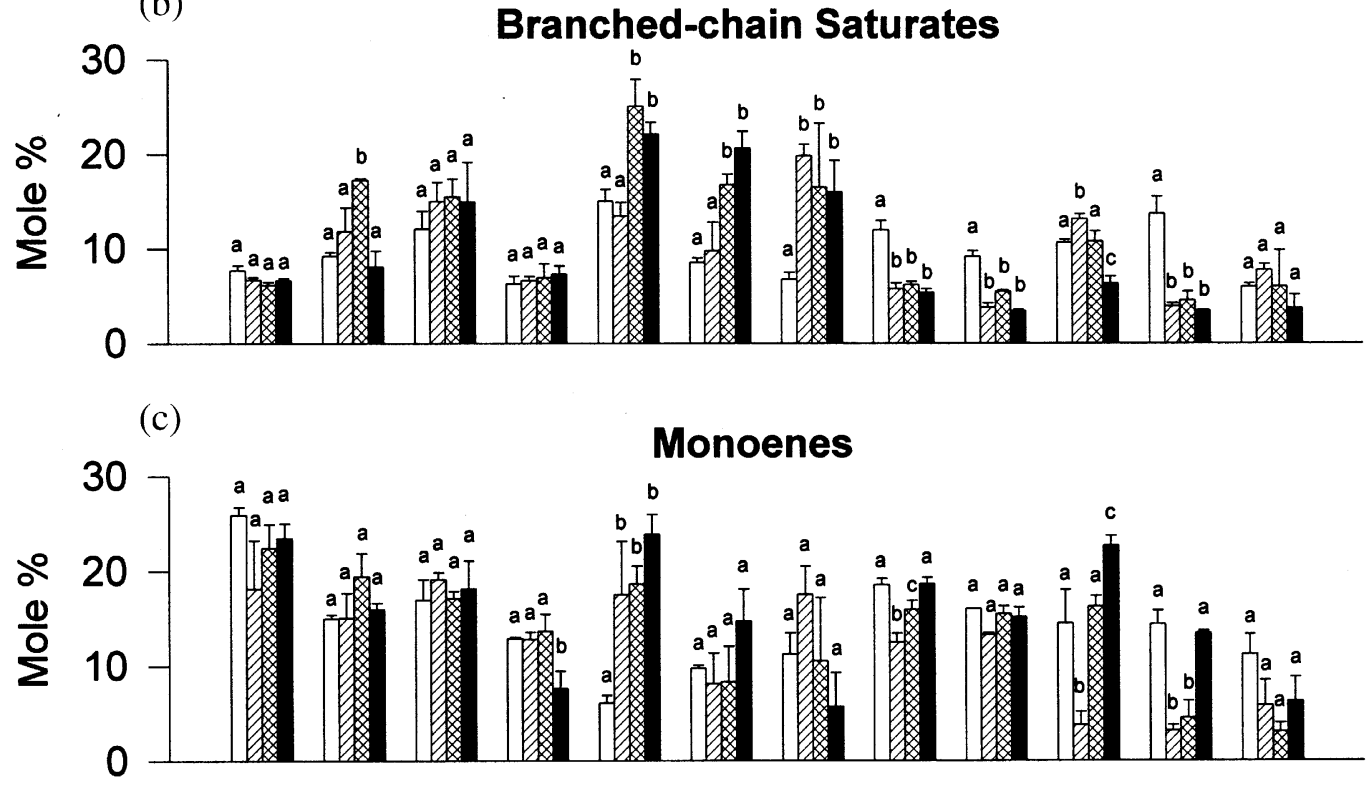

(d) Dienes

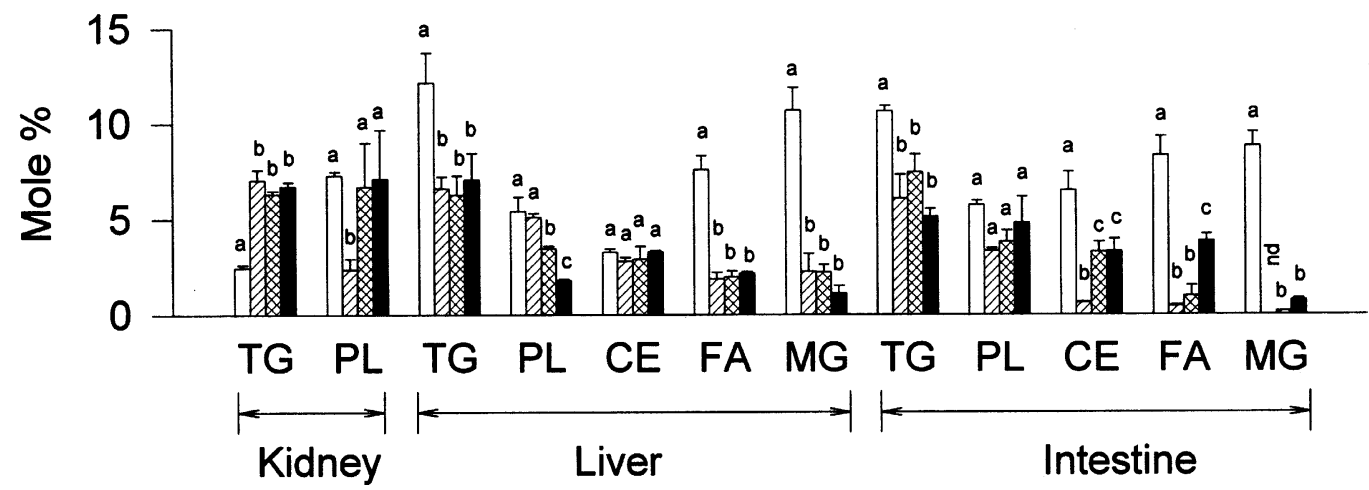

Fig. 1. Changes in saturates (a), branched-chain saturates (b), monoenes (c) and dienes (d) during metamorphosis of landlocked lamprey, Petromyzon marinus. Values are expressed as means \pm S.E.M. $(n=3$ pools, three to four animals per pool $)$. For each lipid class, groups with different letters are significantly different $(P<0.05)$ from each other. 


\section{$\square$ Larva एवागा Stage $3 \times$ Stage $5 \square$ Stage 7}

(a)

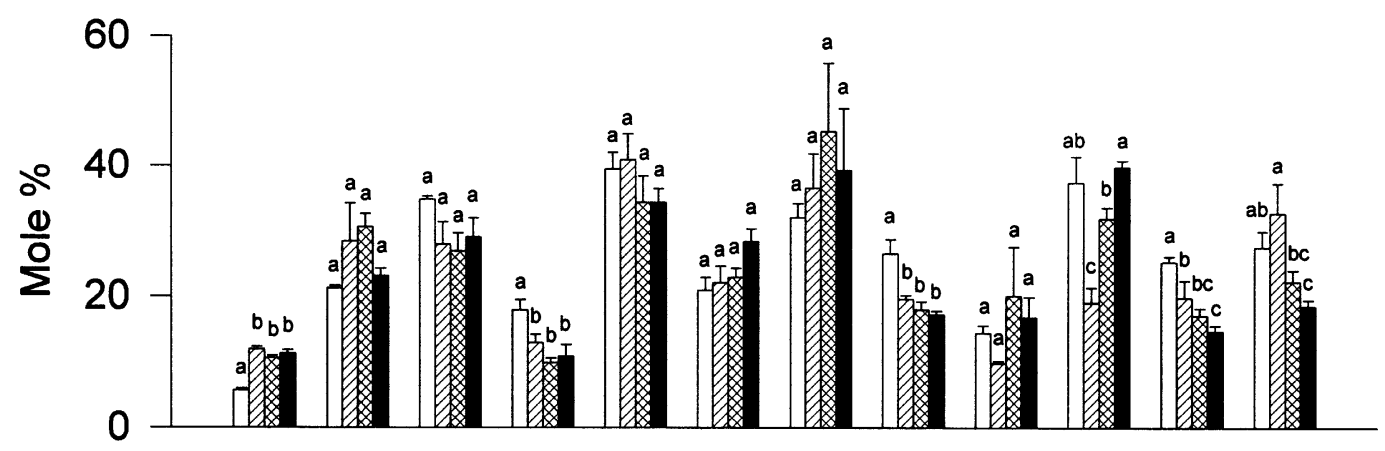

(b)

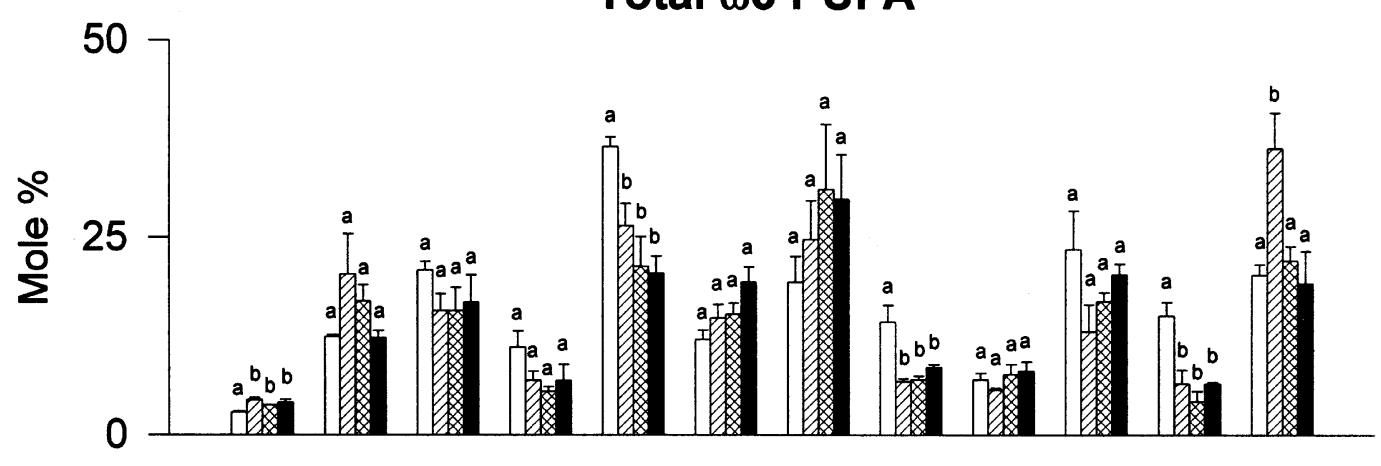

Total 16 PUFA

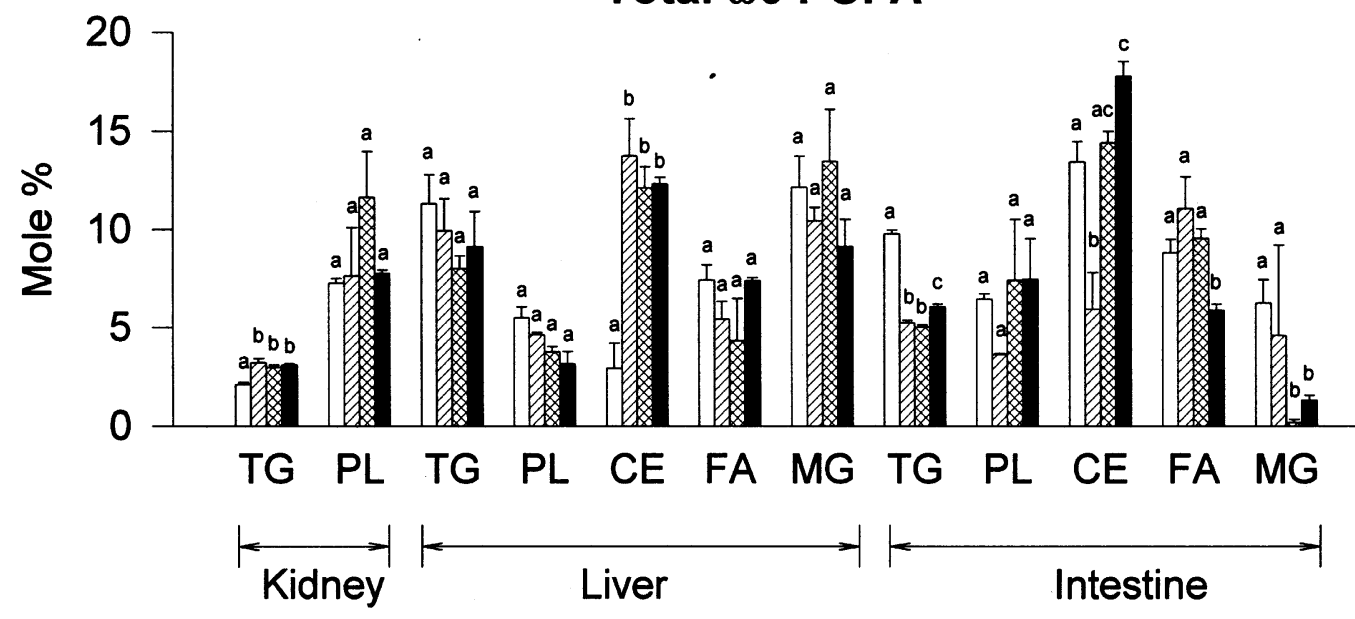

Fig. 2. Changes in total polyunsaturated fatty acids (PUFA; a), total linolenic acid family ( $\omega 3$; b), and total linoleic acid family ( $\omega 6$; c) during metamorphosis of landlocked lamprey, Petromyzon marinus. Values are expressed as means \pm S.E.M. $(n=3$ pools, three to four animals per pool). For each lipid class, groups with different letters are significantly different $(P<0.05)$ from each other. 
$\square$ Larva एवागा Stage 3 Stage $5 \square$ Stage 7

(a) Odd-number Carbon Fatty Acids

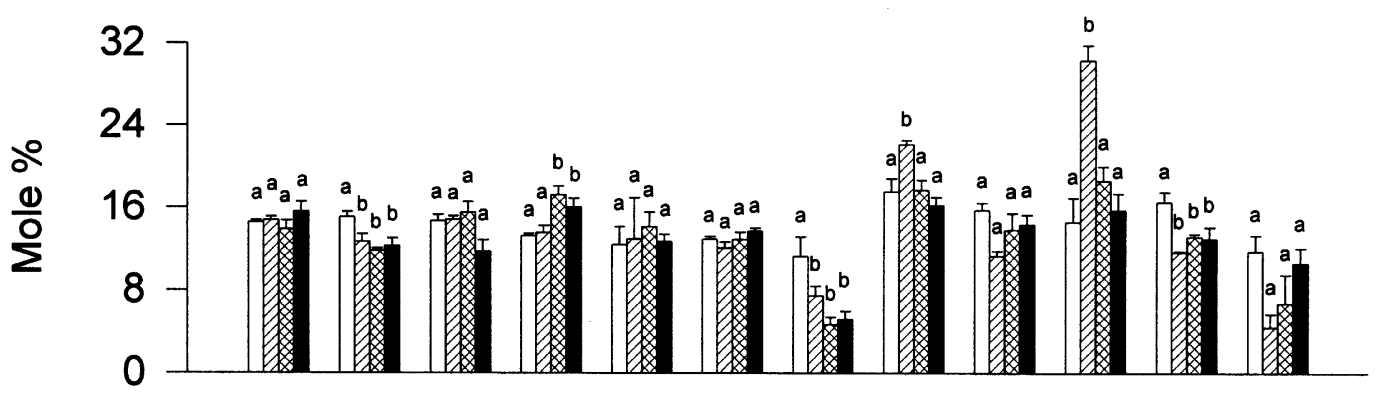

(b) Unsaturation Index

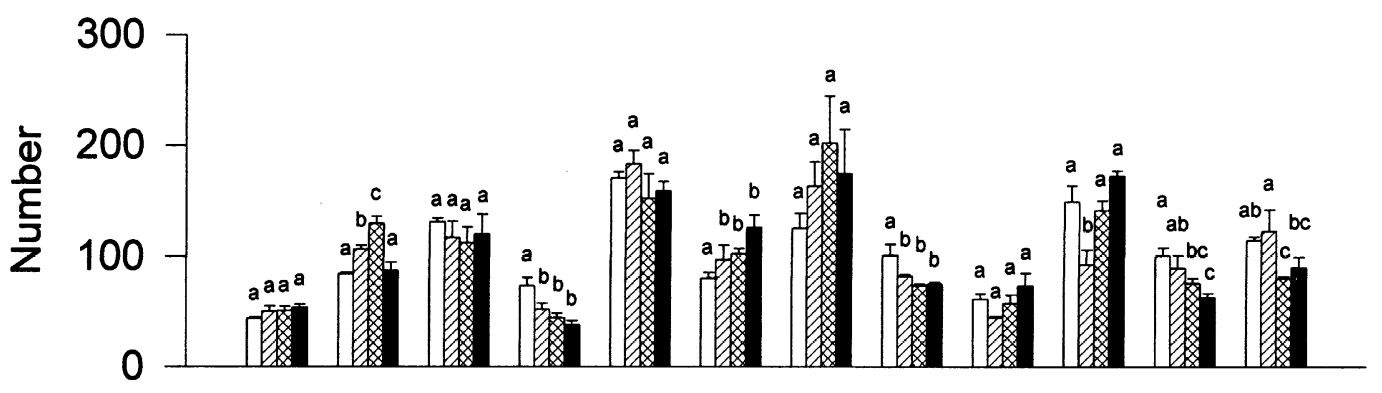

(c) Total Mean Chain Length

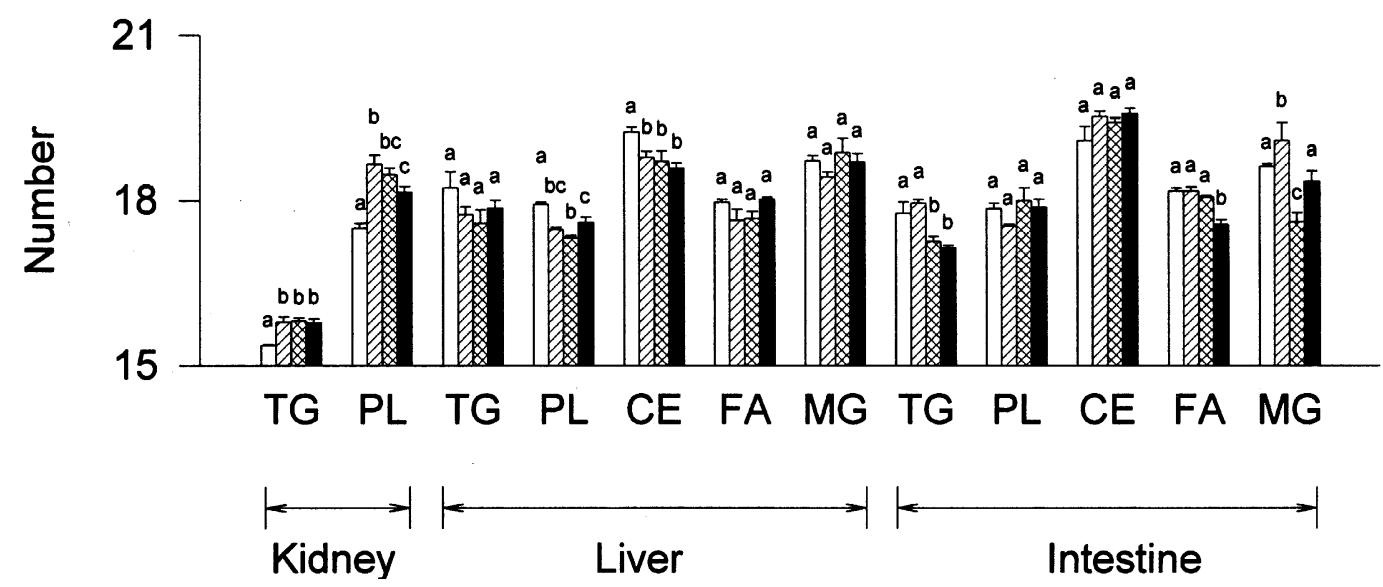

Fig. 3. Changes in the odd-number carbon of fatty acids (a), unsaturation index (b), and total mean chain length (c) during metamorphosis of landlocked lamprey, Petromyzon marinus. Values are expressed as means \pm S.E.M. ( $n=3$ pools, three to four animals per pool). For each lipid class, groups with different letters are significantly different $(P<0.05)$ from each other. 
constituents were significantly changed during metamorphosis. Margaric acid (17:0) abundance decreased significantly from stage 5 to stage 7 . A tendency toward increased abundance of 14:0, 15:0, 16:0 and BCSFA from larvae to stage 7 resulted in slightly increased SFA over the metamorphosis period. As a result, there was a slight drop in USFA/SFA ratio from 1.1 to 0.9. Monoenes, comprised mainly of $18: 1,20: 1$ and $16: 1$, fluctuated little (Fig. 1c) during metamorphosis. Dienes, composed primarily of $18: 2$ and, to a lesser extent, 20:2 and 22:2, tended to decrease from larvae to stage 5 (Fig. 1d). The metamorphosing animals displayed a relatively lower proportion of PUFA than the larvae, primarily due to reduced the abundance of $\omega 3$ (e.g. 18:3 $\omega 3$ and 22:6 $\omega 3$ ) and $\omega 6$ family FA (Table 1, Fig. 2). The $\omega 3 / \omega 6$ ratio in hepatic TG fatty acids fluctuated from 1.6 to 2.0 between the larvae and stage 7 transformer, but was relatively higher than that of renal TG fatty acids. The ONFA, USI and MCL of hepatic TG fatty acids were relatively lower in stage 7 transformer than in larvae (Fig. 3).

The intestinal TG fraction was predominated by 16:0, 17:0, 18:0 and 18:1; the abundance of 16:0 increased from larva to stage 3 coincident with a trend toward decreased abundance of 17:0, 18:0 and 18:1 from larva to stage 7 (Table 1). While BCSFA decreased from larva to stage 7, SFA tended to increase due to alterations in the abundance of 14:0 and 16:0 (Table 1 and Fig. 1). These changes accounted for decreased USFA/ SFA ratio from 0.8 in larva to 0.5 at stage 7 . Monoenes, particularly $16: 1$ and $18: 1$, decreased in abundance from larva to stage 3 and thereafter increased from stage 3 to stage 7 (Fig. 1c), whereas DE (Fig. 1d), particularly 20:2 $\omega 6$, and PUFA (Fig. 2), particularly $\omega 3$ and $\omega 6$ family FA, decreased from larva to stage 7 . The $\omega 3 / \omega 6$ ratio in the intestinal TG class fluctuated from 1.3 in larva to 1.5 at stage 7 transformers. The ONFA decreased from stage 3 to stage 7, whereas USI and MCL decreased significantly in larva to stage 7 transformers (Fig. 3).

\subsection{Phospholipid (PL) fatty acid composition}

Variations in fatty acid composition of the PL fraction also were displayed in kidney, liver, and intestine (Table 2). In the kidney, 16:0 and 18:0 were the predominant fatty acids at each stage; the former tended to decrease in abundance from larva to stage 5 , but the latter tended to increase from larva to stage 7. While BCSFA tended to increase from larva to stage 5, SFA decreased primarily due to 14:0, 15:0 and 16:0 (Table 2, Fig. 1a,b). Thus, a significant rise in the USFA/SFA ratio from 0.6 to 1 was observed. 16:1 decreased in abundance from larva to stage 5, but total ME (Fig. 1c) tended to increase at this period primarily due to a trend toward increased 18:1 and 20:1. Dienes displayed a significant difference between larva to stage 3 and thereafter increased to stage 7 (Fig. 1d). The proportion of PUFA tended to increase from the larva to stage 5, thereby, along with ME, resulting in increased USI over metamorphosis. The $\omega 3 / \omega 6$ ratio slightly increased from 1.7 to 3.7 between the larva and stage 3 due to a greater percentage of $\omega 3$ family (e.g. 18:4 $\omega 3$,

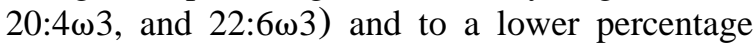

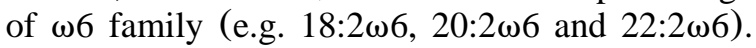
The ONFA was significantly different between larvae and metamorphosing animals, whereas USI and MCL increased significantly from larva and stage 5 and thereafter decreased to stage 7 .

In the liver, 16:0 and 18:0 were the predominant fatty acids of the PL class at each stage, and there was a significant difference in the abundance of 16:0 between larvae and metamorphosing animals. A trend toward increased SAT (Fig. 1a) was observed from larva to stage 7 , and that resulted primarily from changes in the abundance of 16:0 and, to a lesser extent, 14:0, 17:0 and 18:0. Significantly decreased ME (particularly 16:1 and

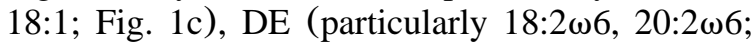

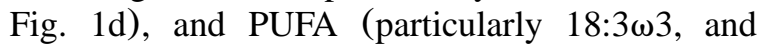
20:3 $\omega 3$ ) accounted for decreased USI (Fig. 3b) during metamorphosis. A tendency toward reduced abundance of $\omega 3$ and $\omega 6$ family FA resulted in a $\omega 3 / \omega 6$ ratio which fluctuated from 1.5 in larva to 2.2 in stage 7 . The MCL was significantly different between larva and stage 5 and between stage 5 and stage 7 (Fig. 3c).

In the intestine, 16:0 and 18:0 were the predominant fatty acid of the PL class at each stage, and the abundance of these constituents fluctuated little during metamorphosis (Table 2). Significant differences between larva and metamorphic animals were noted in the abundance of 18:2, 18:4, 20:0, 20:2, 22:0 and in BCSFA (Fig. 1b). Monoenes, DE, PUFA, ONFA, USI and MCL tended to increase from stage 3 to stage 7 , although these 
Table 2

Fatty acid composition (mol.\%) of phospholipids in the liver, kidney and intestine of lamprey, P. marinus, during metamorphosis ${ }^{\mathrm{a}}$

\begin{tabular}{|c|c|c|c|c|c|c|c|c|c|c|c|c|}
\hline \multirow{2}{*}{$\begin{array}{l}\text { Fatty } \\
\text { acids }\end{array}$} & \multicolumn{4}{|l|}{ Liver } & \multicolumn{4}{|c|}{ Kidney } & \multicolumn{4}{|c|}{ Intestine } \\
\hline & $\bar{L}$ & 3 & 5 & 7 & $\mathrm{~L}$ & 3 & 5 & 7 & $\mathrm{~L}$ & 3 & 5 & 7 \\
\hline $12: 0$ & n.d. & $\operatorname{tr}$ & 0.2 & 0.1 & 0.1 & n.d. & n.d. & $\operatorname{tr}$ & n.d. & 0.1 & 0.2 & $\operatorname{tr}$ \\
\hline $13: 0$ & n.d. & $\operatorname{tr}$ & 0.1 & $\operatorname{tr}$ & 0.4 & n.d. & n.d. & n.d. & n.d. & n.d. & $\operatorname{tr}$ & $\operatorname{tr}$ \\
\hline$n-14: 0^{\mathrm{b}}$ & $0.9^{*}$ & $3.2 * *$ & $3.7 * *$ & $2.8 * *$ & $8.4^{*}$ & $0.2^{* *}$ & $0.8^{* *}$ & $0.8^{* *}$ & $1.5^{*}$ & $2.9^{*}$ & $2.7 *$ & $2.7 *$ \\
\hline$n-15: 0^{\mathrm{b}}$ & $2.0 *$ & $2.6^{*}$ & $3.3^{*}$ & $2.7^{*}$ & $4.4^{*}$ & $1.3^{* *}$ & $1.9 * *$ & $1.6^{* *}$ & $3.0^{*}$ & $2.4^{*}$ & $2.7 *$ & $2.0^{*}$ \\
\hline$n-16: 0^{\mathrm{b}}$ & $17.2^{*}$ & $25.1 * *$ & $25.9 * *$ & $25.5 * *$ & $21.5^{*}$ & $16.8^{* *}$ & $13.7 \dagger$ & $18.2 * *$ & $19.0^{*}$ & $26.9 *$ & $22.6^{*}$ & $21.1^{*}$ \\
\hline$n-17: 0^{\mathrm{b}}$ & $7.3^{*}$ & $6.9^{*}$ & $7.3^{*}$ & $8.4^{* *}$ & $6.1 *$ & $5.5^{*}$ & $6.7 *$ & $5.8^{*}$ & $7.6^{*}$ & $4.8^{*}$ & $6.7 *$ & $5.7 *$ \\
\hline$n-18: 0^{\mathrm{b}}$ & $35.3^{*}$ & $30.3^{*}$ & $30.3 *$ & $34.3^{*}$ & $15.9 *$ & $21.1 *$ & $19.2^{*}$ & $24.6^{*}$ & $30.7 *$ & $31.8^{*}$ & $21.9 *$ & $28.9 *$ \\
\hline $19: 0$ & $2.4^{*}$ & $1.9^{* *}$ & $1.6^{* *}$ & $1.8^{* *}$ & $2.2 *$ & $2.1^{*}$ & $1.4^{*}$ & $2.2 *$ & $2.5^{*}$ & $1.9^{*}$ & $1.2^{*}$ & $3.3^{*}$ \\
\hline $20: 0$ & $1.3^{*}$ & $1.1^{*}$ & $0.9^{*}$ & $1.2 *$ & $1.7 *$ & $1.9 *$ & $1.2^{*}$ & $2.0^{*}$ & $1.6^{*}$ & $1.7 *$ & $1.1^{* *}$ & $0.6^{* *}$ \\
\hline $21: 0$ & $1.2 *$ & $1.3^{*}$ & $1.2^{*}$ & $1.5^{*}$ & $1.2 *$ & $1.9^{*}$ & $1.3^{*}$ & $1.7^{*}$ & $1.5^{*}$ & $1.5^{*}$ & $1.4^{*}$ & $1.5^{*}$ \\
\hline $22: 0$ & $1.1^{*}$ & $0.5^{* *}$ & $0.6^{* *}$ & $1.3^{*}$ & $1.6^{*}$ & $4.4^{*}$ & $2.7 *$ & $2.8^{*}$ & $1.4^{*}$ & $1.4^{*}$ & $1.3^{*}$ & $0.4^{* *}$ \\
\hline $24: 0$ & $0.6^{*}$ & $1.3^{* *}$ & $1.2 * *$ & $1.6^{* *}$ & $0.5^{*}$ & $1.2 * *$ & $1.6^{* *}$ & $1.2 * *$ & $0.5^{*}$ & $1.4^{*}$ & $2.5^{*}$ & $1.6^{*}$ \\
\hline $12: 1 \omega 1$ & n.d. & n.d. & $\operatorname{tr}$ & n.d. & 0.4 & 0.1 & 0.2 & 0.1 & n.d. & n.d. & $\operatorname{tr}$ & $\operatorname{tr}$ \\
\hline $13: 1 \omega 1$ & n.d. & 0.1 & 0.2 & $\operatorname{tr}$ & n.d. & n.d. & n.d. & n.d. & n.d. & $\operatorname{tr}$ & 0.1 & 0.1 \\
\hline $14: 1 \omega 5$ & n.d. & 0.1 & 0.1 & n.d. & 0.1 & n.d. & 0.1 & n.d. & $\operatorname{tr}$ & n.d. & 0.1 & $\operatorname{tr}$ \\
\hline $15: 1 \omega 5$ & n.d. & 0.2 & 0.8 & 0.4 & 0.1 & 0.4 & 0.4 & 0.3 & 0.2 & 0.4 & 0.4 & 0.2 \\
\hline $16: 1 \omega 7^{b}$ & $2.8^{*}$ & $3.8^{* *}$ & $3.2 *$ & $\begin{array}{l}0.7 \\
1.2 \dagger\end{array}$ & $4.0^{*}$ & $0.4^{*}$ & $0.8 * *$ & $2.3 * *$ & $2.5^{*}$ & $2.8^{*}$ & $2.1 *$ & $1.8^{*}$ \\
\hline $17: 1 \omega 9^{b}$ & $\operatorname{tr}$ & 0.1 & 2.4 & 1.1 & 0.7 & n.d. & n.d. & 0.4 & 0.8 & 0.1 & 0.6 & 1.0 \\
\hline $18: 1 \omega 9^{b}$ & $7.2 *$ & $6.0^{*}$ & $4.8^{*, * *}$ & $2.8 * *$ & $7.3^{*}$ & $7.7 *$ & $10.2^{*}$ & $8.2^{*}$ & $8.9^{*}$ & $7.6^{*}$ & $8.5^{*}$ & $7.9^{*}$ \\
\hline $20: 1 \omega 9^{b}$ & $2.1^{*}$ & $1.5^{*}$ & $1.4^{*}$ & $1.3^{*}$ & $1.6^{*}$ & $4.8^{*}$ & $5.6^{*}$ & $3.1^{*}$ & $2.3^{*}$ & $0.9^{*}$ & $1.6^{*}$ & $1.9 *$ \\
\hline $22: 1 \omega 9$ & $0.7^{*}$ & $0.9 *$ & $0.6^{*}$ & $0.7^{*}$ & $0.7 *$ & $(1.2)$ & $2.1 * *$ & $1.5^{* *}$ & $1.2 *$ & $1.4^{*}$ & $1.1^{*}$ & $1.7 *$ \\
\hline $24: 1 \omega 9$ & n.d. & n.d. & n.d. & n.d. & n.d. & 0.4 & n.d. & 0.1 & n.d. & n.d. & 1.0 & 0.5 \\
\hline $18: 2 \omega 6^{\mathrm{b}}$ & $2.8^{*}$ & $3.4^{* *}$ & $2.1 \dagger$ & $0.8 \$$ & $3.4^{*}$ & $0.9^{*}$ & $3.2^{*}$ & $5.0^{*}$ & $2.1^{*}$ & $1.8^{* * * *}$ & $1.3^{* *}$ & $1.6^{*, * *}$ \\
\hline $19: 2 \omega 6$ & n.d. & 0.4 & 0.3 & n.d. & n.d. & n.d. & 0.2 & 0.3 & n.d. & 0.2 & 0.3 & 0.2 \\
\hline $20: 2 \omega 6$ & $2.6^{*}$ & $1.4 * *$ & $1.2 * *$ & $1.0 * *$ & $2.9^{*}$ & $1.4 *$ & $3.3^{*}$ & $1.7 *$ & $3.5^{*}$ & $1.3^{* *}$ & $1.5^{* *}$ & $2.2 * * * *$ \\
\hline $22: 2 \omega 6$ & $\operatorname{tr}$ & n.d. & n.d. & n.d. & 1.0 & 0.1 & n.d. & 0.1 & 0.1 & n.d. & 0.9 & 0.6 \\
\hline $18: 3 \omega 3^{c}$ & $1.4^{*}$ & $1.4^{*}$ & $1.0^{* *}$ & $0.7 \dagger$ & $1.7^{*}$ & $0.5^{*}$ & $1.3^{*}$ & $1.9^{*}$ & $1.1 *$ & $0.7 *$ & $1.0^{*}$ & $0.8^{*}$ \\
\hline $20: 3 \omega 3$ & $1.4 *$ & $1.0 * *$ & $0.9 * *$ & $0.8 * *$ & $1.1^{*}$ & $1.2 *$ & $1.2^{*}$ & $0.7 *$ & $1.3^{*}$ & $0.7 *$ & $0.8^{*}$ & $1.4^{*}$ \\
\hline $20: 3 \omega 6$ & $1.0^{*}$ & $1.0^{*}$ & $0.8^{*}$ & $2.3^{*}$ & $1.1^{*}$ & $1.8^{* *}$ & $1.3^{* * * *}$ & $1.3^{* * * *}$ & $1.1^{*}$ & $0.8^{*}$ & $1.2^{*}$ & $1.7^{*}$ \\
\hline $22: 3 \omega 3^{b}$ & 0.3 & n.d. & 0.1 & n.d. & 0.4 & 1.2 & 1.0 & 1.0 & 0.7 & 0.1 & 1.3 & 0.4 \\
\hline $18: 4 \omega 3$ & $3.4^{*}$ & $2.9^{*}$ & $2.6^{*}$ & $2.8^{*}$ & $3.4^{*}$ & $7.1^{* *}$ & $8.7 * *$ & $4.8^{*}$ & $1.4^{*}$ & $3.2 * * *$ & $5.0 * *$ & $2.7^{* * * *}$ \\
\hline $20: 4 \omega 6^{\mathrm{b}}$ & 1.7 & $(0.5)$ & 0.3 & 1.3 & 2.5 & 5.6 & 4.8 & 2.8 & 1.0 & 0.4 & 2.6 & 3.6 \\
\hline $22: 4 \omega 6^{\mathrm{b}}$ & 0.7 & n.d. & n.d. & n.d. & 1.7 & n.d. & n.d. & n.d. & 0.2 & n.d. & 0.1 & 0.4 \\
\hline $20: 5 \omega 3$ & 0.2 & 0.2 & 0.3 & n.d. & $\operatorname{tr}$ & n.d. & n.d. & n.d. & 0.1 & $\operatorname{tr}$ & n.d. & n.d. \\
\hline $21: 5 \omega 2$ & n.d. & n.d. & n.d. & n.d. & n.d. & n.d. & n.d. & n.d. & n.d. & n.d. & 0.5 & 0.2 \\
\hline $22: 5 \omega 3^{b}$ & 0.7 & n.d. & n.d. & n.d. & $0.4^{*}$ & $2.6^{* * * *}$ & $4.3 * *$ & $1.4^{*}$ & $0.5^{*}$ & n.d. & 1.3 & 0.2 \\
\hline $22: 6 \omega 3$ & $1.7 *$ & $0.5^{*}$ & $0.4^{*}$ & $1.2 *$ & $1.5^{*}$ & $5.9^{*}$ & $0.9^{*}$ & $1.2^{*}$ & $1.4^{*}$ & $0.5^{*}$ & $2.4^{*}$ & $0.8^{*}$ \\
\hline
\end{tabular}

${ }^{a}$ Data are expressed as means of determinations made on three pooled samples; three lampreys per pool. Fatty acids representing inside the parenthesis were obtained only from one out of three pooled samples. S.E.M.s are omitted for clarity. For each fatty acid composition, groups with different symbol designations $(*, * *, \dagger$ and $\ddagger)$ for a particular tissue are significantly different $(P<0.05)$. n.d., not detectable; tr, trace amount $(<0.1 \%)$.

${ }^{\mathrm{b}}$ Isomers may be present; the predominant one is reported here but value is the summation of these isomers. For example, 14:0 comprises iso-, normal- and anteiso-14:0, etc. Those isomers in the unsaturated fatty acid composition can be attributed to the double

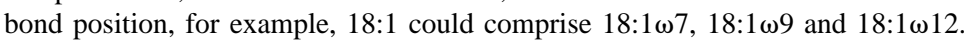

${ }^{\mathrm{c}}$ No distinction could be made between $18: 3 \omega 3$ and 19:1 $\omega 9$ in the analysis and the peak was assigned to $18: 3 \omega 3$ only.

changes were not significant (Figs. 1-3). The $\omega 3$ / $\omega 6$ ratio varied significantly during the metamorphosis, including an increase from larva (1.1) to stage 5 (1.7) and a decrease to stage 7 (1.2). The $\omega 3$ family, particularly $18: 4 \omega 3$, and $\omega 6$ family, particularly $20: 4 \omega 6$, both tended to increase from 
the larva to stage 7 , whereas $18: 2 \omega 6$ and $20: 2 \omega 6$ decreased over the metamorphosis (Table 2).

\subsection{Cholesteryl ester (CE) fatty acid composition}

The fatty acid compositions of the CE class in the liver and intestine changed during lamprey metamorphosis (Table 3). In the liver, 16:0, 18:0, $18: 1,18: 4 \omega 3$, and $20: 4 \omega 3$ were observed as predominant; of these, the abundance of $18: 0$ and 18:1 differed significantly between larva and stage 7. A tendency toward decreased SFA accompanied metamorphosis while BCSFA significantly increased (Fig. 1). Monoenes (Fig. 1c; particularly 18:1) tended to increase from larva to stage 7 , while PUFA (Fig. 2a; particularly 20:2 $\omega 6,20: 3 \omega 3$ and 22:6 03 ) tended to decrease, resulting in increased ME/PUFA ratio from 0.2 to 0.7 over metamorphosis. A trend toward decreased PUFA was primarily due to the significantly reduced $\omega 3$

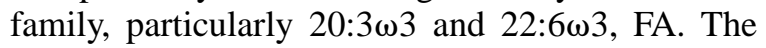
$\omega 6$ family displayed a significant difference between larvae and stage 3 (Fig. 2c). The MCL decreased significantly from larva to stage 7 (Fig. $3 c)$.

In the intestine, the predominant fatty acids of the CE fraction were 16:0, 17:0, 18:0, 18:1, 19:0 and 24:0; 17:0, 18:0, 19:0 and 24:0 significantly decreased in abundance from stage 3 to stage 7 (Table 3). The abundance of both $20: 2 \omega 6$ and 20:3 $\omega 3$ significantly differed from larvae to stage 7. As indicated in Figs. 1-3, BCSFA, SFA and ONFA (particularly 17:0) decreased significantly from stage 3 to stage 7, while increased $\mathrm{ME}, \mathrm{DE}$, PUFA and USI were observed. All these parameters also displayed a significant difference between larva and stage 3 .

\subsection{Fatty acid composition of the fatty acid (FA) class}

The compositions of liver and intestine FA class were altered during lamprey metamorphosis (Table 4). The predominant non-esterified FAs in the liver were 16:0 and 18:0. Although BCSFA increased significantly from stage 3 to stage 7 , SFA, due to a lower proportion of 16:0, tended to decrease from stage 5 to stage 7 . As a result, the USFA/ SFA ratio increased from 0.5 to 0.8 . Monoenes tended to increase during metamorphosis primarily due to changes in the abundance of 20:1, although 16:1 abundance significantly decreased. Dienes, particularly $18: 2 \omega 6$ and 20:2 $\omega 6$, decreased significantly from larva to stage 7 , whereas PUFA,

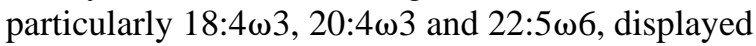
significant differences between larva and stage 3 . The $\omega 3 / \omega 6$ ratio tended to increase from 1.6 in larva to 2.6 at stage 7 . The MCL and ONFA fluctuated from larva to stage 7 while USI significantly increased (Fig. 3).

The intestinal FA class also was predominated by 16:0 and 18:0; both of these FA were relatively higher in abundance in metamorphic animals than in larvae. Significant differences in SFA occurred between larva and stage 7, while BCSFA, USFA, DE, PUFA ( $\omega 3$ and $\omega 6$ families), ONFA (particularly 17:0), USI and MCL all significantly decreased (Figs. 1-3). Increased SFA was primarily due to increased abundance of 16:0 and 18:0. Monoenes, particularly 18:1, increased significantly from stage 3 to stage 7 . Significant alterations in the abundance of 20:2 $\omega 6$ was observed between larva and stage 7; significant alterations in 18:3 $\omega 3$,

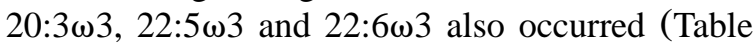
4).

\subsection{Monoacylglycerol (MG) fatty acid composition}

The fatty acid compositions of liver and intestine MG class also changed during lamprey metamorphosis (Table 5). The hepatic MG class was

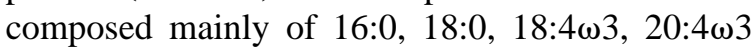

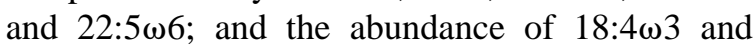

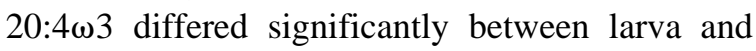
metamorphic animals. The abundance of $18: 3 \omega 3$ and 20:3 $\omega 3$ also displayed significant differences between larva and metamorphic animals (Table 5). As indicated in Figs. 1-3, metamorphosis from larva to stage 7 was accompanied by a trend toward decreased ME (e.g. 18:1 and 20:1), DE

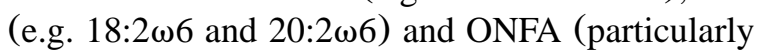
17:0) and increased BCSFA, PUFA (particularly $\omega 3$ family) and USI.

Intestinal MG was predominated by four fatty acids, 16:0, 18:0, 18:3 $\omega 3$ and 22:0. Accompanying lamprey metamorphosis from stage 3 to stage 7 was a trend toward increased SFA (particularly 16:0) and ONFA and decreased BCSFA, USFA, PUFA ( $\omega 3$ and $\omega 6$ families), USI and MCL (Figs. $1-3)$. Monoenes and DE tended to decrease from larvae and stage 7 (Fig. 1c,d). 
Table 3

Fatty acid composition (mol.\%) of cholesteryl ester in the liver and intestine of lamprey, P. marinus, during metamorphosis ${ }^{\mathrm{a}}$

\begin{tabular}{|c|c|c|c|c|c|c|c|c|}
\hline \multirow{2}{*}{$\begin{array}{l}\text { Fatty } \\
\text { acids }\end{array}$} & \multicolumn{4}{|l|}{ Liver } & \multicolumn{4}{|c|}{ Intestine } \\
\hline & $\mathrm{L}$ & 3 & 5 & 7 & $\mathrm{~L}$ & 3 & 5 & 7 \\
\hline $12: 0$ & n.d. & n.d. & $\operatorname{tr}$ & 0.2 & n.d. & n.d. & n.d. & n.d. \\
\hline 13:0 & n.d. & n.d. & 0.1 & 0.1 & n.d. & n.d. & n.d. & n.d. \\
\hline$n-14: 0^{\mathrm{b}}$ & $(0.4)$ & $0.6^{*}$ & $1.3^{*}$ & $1.8^{*}$ & n.d. & $0.7 *$ & $0.5^{*}$ & $0.8^{*}$ \\
\hline$n-15: 0^{\mathrm{b}}$ & n.d. & $1.3^{*}$ & $2.6^{*}$ & $2.8^{*}$ & $0.7 *$ & $1.7 *$ & $1.4^{*}$ & $1.2 *$ \\
\hline$n-16: 0^{\mathrm{b}}$ & $7.6^{*}$ & $11.3 *$ & $10.9 *$ & $9.6^{*}$ & $9.0^{*}$ & $10.4^{*}$ & $12.1 *$ & $9.3^{*}$ \\
\hline$n-17: 0^{\mathrm{b}}$ & $9.2 *$ & $7.1^{*}$ & $9.1 *$ & $7.9^{*}$ & $10.1^{*}$ & $9.3^{*}$ & $9.6^{*}$ & $6.2 * *$ \\
\hline$n-18: 0^{\mathrm{b}}$ & $20.9^{*}$ & $13.1^{* *}$ & $14.0^{* *}$ & $12.2 * *$ & $15.5^{*}$ & $17.8^{*}$ & $10.5^{* *}$ & $4.7 \dagger$ \\
\hline 19:0 & n.d. & n.d. & 0.2 & 0.2 & $1.2^{*}$ & $13.2 * *$ & $3.5^{*}$ & $1.4^{*}$ \\
\hline 20:0 & $3.7 *$ & $2.0^{*}$ & $1.6^{*}$ & $2.1^{*}$ & $2.8^{*}$ & $2.0^{*}$ & $1.4^{* * * *}$ & $1.2 * *$ \\
\hline 21:0 & $4.1 *$ & $1.1 * *$ & $1.5 * *$ & $0.8 * *$ & $2.7 *$ & $5.4^{*}$ & $3.4^{*}$ & $4.6^{*}$ \\
\hline $22: 0$ & $4.2 *$ & $1.7 * *$ & $1.5^{* *}$ & $1.5^{* *}$ & $2.7 *$ & $5.0^{* *}$ & $2.4^{*}$ & $1.9 *$ \\
\hline $24: 0$ & $4.2^{*}$ & $3.3^{*}$ & $4.2 *$ & $2.7^{*}$ & $3.3^{*}$ & $11.4 * *$ & $7.1 \dagger$ & $6.2 * \dagger$ \\
\hline $12: 1 \omega 1$ & n.d. & n.d. & 0.3 & 0.5 & n.d. & n.d. & n.d. & n.d. \\
\hline $13: 1 \omega 1$ & n.d. & n.d. & 0.2 & 0.3 & n.d. & n.d. & n.d. & n.d. \\
\hline $14: 1 \omega 5$ & n.d. & n.d. & 0.1 & n.d. & n.d. & n.d. & n.d. & n.d. \\
\hline $15: 1 \omega 5$ & n.d. & 0.5 & 0.5 & 0.7 & n.d. & 0.9 & 0.4 & 0.2 \\
\hline $16: 1 \omega 7^{b}$ & n.d. & $0.6^{*}$ & $0.6^{*}$ & $0.2^{*}$ & $1.5^{*}$ & n.d. & $0.6^{*}$ & $1.6^{*}$ \\
\hline $17: 1 \omega 9$ & n.d. & 3.0 & n.d. & n.d. & n.d. & n.d. & n.d. & 0.7 \\
\hline $18: 1 \omega 9^{b}$ & $6.1^{*}$ & $8.1 * * *$ & $10.2 * *$ & $12.8^{* *}$ & $11.1^{*}$ & $(0.5)$ & $9.3^{*}$ & $13.2 *$ \\
\hline $20: 1 \omega 9^{b}$ & n.d. & $4.6^{*}$ & $4.6^{*}$ & $8.5^{*}$ & 1.3 & $(0.3)$ & $(0.3)$ & 1.8 \\
\hline $22: 1 \omega 9$ & n.d. & $0.8^{*}$ & $0.6^{*}$ & $0.6^{*}$ & $0.6^{*}$ & n.d. & $1.5^{*}$ & $1.8^{*}$ \\
\hline $24: 1 \omega 9$ & n.d. & n.d. & 1.6 & 0.3 & n.d. & 2.4 & 4.3 & 3.6 \\
\hline $18: 2 \omega 6^{\mathrm{b}}$ & n.d. & $2.0^{*}$ & $2.2^{*}$ & $2.7^{*}$ & $1.0^{*}$ & n.d. & $0.8^{*}$ & $2.3^{*}$ \\
\hline $19: 2 \omega 6$ & n.d. & n.d. & n.d. & n.d. & n.d. & n.d. & n.d. & 0.3 \\
\hline $20: 2 \omega 6$ & $2.2 *$ & $0.8 * *$ & $0.7 * *$ & $0.6^{* *}$ & $5.5^{*}$ & $0.6^{* *}$ & $1.8 * *$ & $2.1 * *$ \\
\hline $22: 2 \omega 6$ & n.d. & n.d. & n.d. & n.d. & n.d. & n.d. & 0.4 & n.d. \\
\hline $18: 3 \omega 3^{c}$ & n.d. & $(1.5)$ & $0.5^{*}$ & $0.6^{*}$ & n.d. & n.d. & 0.5 & 0.2 \\
\hline $20: 3 \omega 3$ & $3.2 *$ & $0.4 * *$ & $0.7 * *$ & $0.4 * *$ & $3.0^{*}$ & $0.9 * *$ & $1.3^{* *}$ & $1.7 * *$ \\
\hline $20: 3 \omega 6^{\mathrm{b}}$ & $0.7 *$ & $1.2^{*}$ & $1.7 *$ & $1.7^{*}$ & $3.1 *$ & n.d. & $2.1 * *$ & $3.8^{*}$ \\
\hline $22: 3 \omega 3$ & n.d. & n.d. & 0.5 & n.d. & 3.2 & n.d. & 2.1 & 3.1 \\
\hline $22: 3 \omega 6$ & n.d. & 1.5 & 2.1 & 1.6 & 2.7 & 2.4 & 3.9 & 4.8 \\
\hline $18: 4 \omega 3$ & $9.2 *$ & $12.8^{*}$ & $9.2^{*}$ & $9.3^{*}$ & $4.6^{*}$ & $2.1^{*}$ & $3.5^{*}$ & $4.7 *$ \\
\hline $20: 4 \omega 3$ & $10.1^{*}$ & $11.8^{*}$ & $8.4^{*}$ & $8.5^{*}$ & $4.2 *$ & n.d. & $1.9^{*}$ & $3.6^{*}$ \\
\hline $20: 4 \omega 6$ & n.d. & $1.0 *$ & $1.4^{*}$ & $1.1^{*}$ & $1.5^{*}$ & $3.0^{*}$ & $2.8^{*}$ & $4.2 *$ \\
\hline $22: 4 \omega 6$ & 6.5 & n.d. & n.d. & n.d. & 1.2 & n.d. & n.d. & n.d. \\
\hline $20: 5 \omega 3$ & n.d. & n.d. & n.d. & n.d. & n.d. & 0.8 & 0.2 & 0.1 \\
\hline $21: 5 \omega 2$ & n.d. & n.d. & n.d. & n.d. & n.d. & n.d. & 0.5 & 1.3 \\
\hline $22: 5 \omega 3$ & n.d. & n.d. & 5.6 & $6.6^{*}$ & $3.7 *$ & $2.5^{*}$ & $3.4^{*}$ & $3.8^{*}$ \\
\hline $22: 5 \omega 6$ & n.d. & 8.0 & 4.6 & 5.9 & n.d. & n.d. & 1.7 & 1.7 \\
\hline $22: 6 \omega 3$ & $7.7 *$ & $1.6^{* *}$ & $1.1^{* *}$ & $1.0^{* *}$ & $3.7 *$ & $6.8^{*}$ & $4.2 *$ & $3.3^{*}$ \\
\hline
\end{tabular}

a,b,c See the footnotes of Table 1 and Table 2 .

\subsection{Diacylglycerol (DG) fatty acid composition}

Changes in the fatty acid compositions in the DG fraction of intestine (stages 3,5 and 7) accompanied lamprey metamorphosis (Table 6). Palmitic acid and 18:0 were the primary constituents. There was a greater mole percentage of SFA at stage 7 than at stage 3 while USFA (particularly
PUFA) decreased. Due to the high amount of

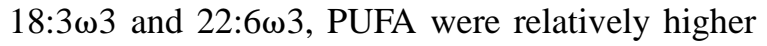
than ME when observed at each stage.

\section{Discussion}

The results from this study indicated that changes in the fatty acid composition of the selected 
Table 4

Fatty acid composition (mol.\%) of free fatty acids in the liver and intestine of lamprey, P. marinus, during metamorphosis ${ }^{\mathrm{a}}$

\begin{tabular}{|c|c|c|c|c|c|c|c|c|}
\hline \multirow{2}{*}{$\begin{array}{l}\text { Fatty } \\
\text { acids }\end{array}$} & \multicolumn{4}{|l|}{ Liver } & \multicolumn{4}{|c|}{ Intestine } \\
\hline & $\mathrm{L}$ & 3 & 5 & 7 & $\mathrm{~L}$ & 3 & 5 & 7 \\
\hline $12: 0$ & n.d. & 0.2 & n.d. & n.d. & n.d. & n.d. & n.d. & n.d. \\
\hline 13:0 & n.d. & n.d. & n.d. & 0.2 & n.d. & n.d. & n.d. & n.d. \\
\hline$n-14: 0^{\mathrm{b}}$ & $0.4 *$ & $3.2 *$ & $3.6^{*}$ & $1.7^{*}$ & $0.6^{*}$ & n.d. & $0.4^{*}$ & $2.3^{*}$ \\
\hline$n-15: 0^{\mathrm{b}}$ & $2.3^{*}$ & $2.9^{*}$ & $4.2^{*}$ & $3.2^{*}$ & $2.7^{*}$ & $0.5^{*}$ & $1.7^{*}$ & $2.6^{*}$ \\
\hline$n-16: 0^{\mathrm{b}}$ & $24.7 *$ & $34.6^{*}$ & $32.3 *$ & $20.4^{*}$ & $19.7 *$ & $30.8 * *$ & $34.6 \mathrm{c}$ & $30.4 * *$ \\
\hline$n-17: 0^{\mathrm{b}}$ & $7.7^{*}$ & $6.7 *$ & $7.1^{*}$ & $8.3^{*}$ & $8.8^{*}$ & $6.5^{* *}$ & $6.1 * *$ & $5.5^{* *}$ \\
\hline$n-18: 0^{\mathrm{b}}$ & $26.2^{*}$ & $18.9 * *$ & $18.3 * *$ & $18.5^{* *}$ & $19.2 *$ & $27.8 *$ & $22.9^{*}$ & $24.5^{*}$ \\
\hline 19:0 & $1.9 *$ & $1.3^{*}$ & $2.8^{*}$ & $0.7 *$ & $2.9 *$ & $0.3 * *$ & n.d. & $1.3 * *$ \\
\hline 20:0 & $2.1^{*}$ & $1.0 * *$ & $1.0 * *$ & $0.7 * *$ & $1.8^{*}$ & $2.1^{*}$ & $1.5^{*}$ & $0.7 * *$ \\
\hline 21:0 & $1.2 *$ & $0.9^{*}$ & $0.9^{*}$ & $0.8^{*}$ & $1.8^{*}$ & $1.4^{*}$ & $1.5^{*}$ & $0.8^{*}$ \\
\hline $22: 0$ & $1.7 *$ & $1.3^{*}$ & $1.6^{*}$ & $0.5^{*}$ & $1.7 *$ & $(0.2)$ & $4.6^{*}$ & $2.0^{*}$ \\
\hline 24:0 & $1.1^{*}$ & $3.6^{*}$ & $3.2^{*}$ & $2.1^{*}$ & $1.1^{*}$ & $7.4 * *$ & $5.1 \mathrm{c}$ & $1.6^{*}$ \\
\hline $12: 1 \omega 1$ & n.d. & 0.1 & 0.2 & 0.4 & n.d. & n.d. & n.d. & n.d. \\
\hline $13: 1 \omega 1$ & n.d. & n.d. & 0.1 & 0.2 & n.d. & n.d. & n.d. & n.d. \\
\hline $14: 1 \omega 5$ & n.d. & n.d. & n.d. & 0.1 & n.d. & n.d. & n.d. & n.d. \\
\hline $15: 1 \omega 5$ & n.d. & 0.3 & 0.6 & 0.3 & $\operatorname{tr}$ & 0.7 & 0.7 & 0.4 \\
\hline $16: 1 \omega 7^{b}$ & $2.2 *$ & $1.4^{* * * *}$ & $0.4 * *$ & $0.6 * *$ & $2.3^{*}$ & n.d. & $(0.6)$ & 3.0 ** \\
\hline $17: 1 \omega 9^{\mathrm{b}}$ & n.d. & n.d. & n.d. & n.d. & 0.6 & n.d. & 1.1 & 0.6 \\
\hline $18: 1 \omega 9^{\mathrm{b}}$ & $6.6^{*}$ & $4.0^{*}$ & $3.8^{*}$ & $7.3^{*}$ & $8.0 *$ & $1.4 * *$ & $1.0 * *$ & $6.8^{*}$ \\
\hline $20: 1 \omega 9^{b}$ & $1.0^{*}$ & $2.3^{*}$ & $3.1^{*}$ & $5.7 *$ & $2.9 *$ & $0.6^{*}$ & $1.2 *$ & $1.9^{*}$ \\
\hline $22: 1 \omega 9$ & n.d. & n.d. & 0.1 & 0.1 & $0.2^{*}$ & $0.4^{*}$ & n.d. & $0.8^{*}$ \\
\hline $24: 1 \omega 9$ & n.d. & n.d. & n.d. & n.d. & 0.2 & n.d. & n.d. & n.d. \\
\hline $18: 2 \omega 6^{\mathrm{b}}$ & $3.0 *$ & $1.2 * *$ & $0.9 * *$ & $1.8^{* *}$ & $2.9^{*}$ & n.d. & $(1.2)$ & $2.3^{*}$ \\
\hline $19: 2 \omega 6$ & n.d. & 0.1 & 0.1 & 0.1 & n.d. & n.d. & n.d. & 0.1 \\
\hline $20: 2 \omega 6$ & $2.8^{*}$ & $0.6^{* *}$ & $0.3 * *$ & $0.3 * *$ & $3.9^{*}$ & $0.4 * *$ & $0.4 * *$ & $1.2 * *$ \\
\hline $22: 2 \omega 6$ & 1.8 & n.d. & n.d. & n.d. & 1.6 & n.d. & 0.4 & 0.3 \\
\hline $18: 3 \omega 3^{c}$ & $1.6^{*}$ & $0.8^{* *}$ & $0.3 * *$ & $0.9 * *$ & $1.9^{*}$ & n.d. & $(0.1)$ & $0.9 * *$ \\
\hline $20: 3 \omega 3$ & $1.3^{*}$ & $0.4 * *$ & $0.3 * *$ & $0.4 * *$ & $1.6^{*}$ & $0.3 * *$ & $0.4 * *$ & $0.8^{* * *}$ \\
\hline $20: 3 \omega 6^{b}$ & $1.0^{*}$ & $0.6^{*}$ & $0.5^{*}$ & $0.9 *$ & $1.3^{*}$ & n.d. & $0.3 * *$ & $0.7 \mathrm{c}$ \\
\hline $22: 3 \omega 3$ & 0.7 & n.d. & n.d. & n.d. & 0.4 & 0.7 & 0.8 & 0.2 \\
\hline $22: 3 \omega 6$ & 0.3 & 1.0 & 0.7 & 1.2 & n.d. & 1.1 & 1.0 & 0.5 \\
\hline $18: 4 \omega 3$ & $2.8^{*}$ & $5.2 * *$ & $5.1 * *$ & $9.8 \mathrm{c}$ & $3.9^{*}$ & $0.4 * *$ & $0.6^{* *}$ & $3.0^{*}$ \\
\hline $20: 4 \omega 6$ & n.d. & n.d. & n.d. & n.d. & 0.2 & 0.7 & 0.1 & n.d. \\
\hline $20: 4 \omega 3$ & $1.0^{*}$ & $3.6^{* *}$ & $3.9 * *$ & $7.5 \mathrm{c}$ & $1.5^{*}$ & n.d. & $(0.1)$ & $0.8^{*}$ \\
\hline $22: 4 \omega 6$ & 0.4 & n.d. & n.d. & n.d. & 0.7 & n.d. & 0.1 & n.d. \\
\hline $20: 5 \omega 3$ & n.d. & n.d. & n.d. & n.d. & n.d. & 0.3 & n.d. & n.d. \\
\hline $21: 5 \omega 2$ & n.d. & n.d. & n.d. & n.d. & n.d. & 2.3 & 3.3 & 1.6 \\
\hline $22: 5 \omega 3$ & $1.2^{*}$ & n.d. & n.d. & n.d. & $3.5^{*}$ & n.d. & n.d. & $0.2^{*}$ \\
\hline $22: 5 \omega 6$ & n.d. & $2.6 * *$ & $2.6 * *$ & $4.7 * *$ & n.d. & n.d. & n.d. & n.d. \\
\hline $22: 6 \omega 3$ & $3.0 *$ & $1.2 *$ & $2.1^{*}$ & $0.7^{*}$ & $2.0 *$ & $4.3^{* *}$ & $2.2 *$ & $0.6 c$ \\
\hline
\end{tabular}

a,b,c See the footnotes of Table 1 and Table 2 .

lipid classes from the kidney, liver and intestine of sea lamprey accompany metamorphosis. Alterations in fatty acid compositions of plasma, whole body and of selected tissues (liver, gonad, muscle) during various periods of the life cycles of several lamprey species, including pre-metamorphic (lar- vae), post-metamorphic (downstream migrants), pre-breeding (upstream migrants) and breeding period (adult), have been reported previously (Fellows and Mclean, 1982; Bird and Potter, 1983; Whyte et al., 1993; Bird et al., 1993; LeBlanc et al., 1995). This study is the first report of altera- 
Table 5

Fatty acid composition (mol.\%) of monoacylglycerol in the liver and intestine of lamprey, P. marinus, during metamorphosis ${ }^{\mathrm{a}}$

\begin{tabular}{|c|c|c|c|c|c|c|c|c|}
\hline \multirow{2}{*}{$\begin{array}{l}\text { Fatty } \\
\text { acids }\end{array}$} & \multicolumn{4}{|l|}{ Liver } & \multicolumn{4}{|l|}{ Intestine } \\
\hline & $\mathrm{L}$ & 3 & 5 & 7 & $\mathrm{~L}$ & 3 & 5 & 7 \\
\hline$n-14: 0^{\mathrm{b}}$ & n.d. & $1.9^{*}$ & $1.1 *$ & $0.8^{*}$ & n.d. & n.d. & 0.4 & 1.0 \\
\hline$n-15: 0^{\mathrm{b}}$ & $0.3^{*}$ & $3.3^{*}$ & $1.4^{*}$ & $1.4^{*}$ & $1.0^{*}$ & n.d. & $1.5^{*}$ & $2.1^{* *}$ \\
\hline$n-16: 0^{\mathrm{b}}$ & $18.8^{*}$ & $17.4^{*}$ & $14.5^{*}$ & $18.4^{*}$ & $21.1^{* * * *}$ & $11.6^{*}$ & $29.1 * *$ & $29.2 * *$ \\
\hline$n-17: 0^{\mathrm{b}}$ & $7.2 *$ & $1.4 * *$ & $1.7 * *$ & $2.3 * *$ & $7.6^{*}$ & $2.6^{* *}$ & $2.3 * *$ & $3.6^{* *}$ \\
\hline$n-18: 0^{\mathrm{b}}$ & $18.3^{*}$ & $14.9^{*}$ & $17.7^{*}$ & $23.4^{*}$ & $17.5^{*}$ & $22.4^{*}$ & $19.2^{*}$ & $19.4^{*}$ \\
\hline 19:0 & $2.0 *$ & $0.6^{*}$ & $0.3 * *$ & $0.1 * *$ & 1.6 & n.d. & n.d. & n.d. \\
\hline $20: 0$ & $2.7^{*}$ & $1.9 * *$ & $1.2^{*}$ & $1.9 *$ & $3.8^{*}$ & $0.8 * *$ & $1.3 * *$ & $1.5^{* *}$ \\
\hline 21:0 & $2.6 *$ & $1.0 *$ & $0.4^{* *}$ & $0.6^{* *}$ & $1.6^{*}$ & $0.5^{*}$ & $0.8^{*}$ & $2.2 *$ \\
\hline $22: 0$ & $2.3^{*}$ & $1.9^{*}$ & $2.9^{*}$ & $1.7^{*}$ & $3.3^{*}$ & $10.3^{*}$ & $17.1^{*}$ & $7.8^{*}$ \\
\hline $24: 0$ & $2.4^{*}$ & $1.5^{*}$ & $2.9^{*}$ & $4.4^{*}$ & $3.6^{*}$ & $4.9^{*}$ & $2.9^{*}$ & $5.1^{*}$ \\
\hline $12: 1 \omega 1$ & 0.2 & 0.4 & 0.2 & 0.1 & n.d. & n.d. & n.d. & n.d. \\
\hline $13: 1 \omega 1$ & n.d. & 0.2 & n.d. & n.d. & n.d. & n.d. & n.d. & n.d. \\
\hline $15: 1 \omega 5$ & n.d. & 0.6 & 0.9 & 0.6 & n.d. & 1.3 & 2.2 & 1.5 \\
\hline $16: 1 \omega 7^{b}$ & 0.4 & 0.6 n.d. & 0.3 & $1.1^{*}$ & n.d. & n.d. & $0.8^{*}$ & \\
\hline $18: 1 \omega 9^{b}$ & $8.2 *$ & $7.3^{*}$ & $4.4^{*}$ & $(1.7)$ & $9.6^{*}$ & n.d. & $0.8^{* *}$ & $0.8^{* *}$ \\
\hline $20: 1 \omega 9^{b}$ & $(0.8)$ & $7.9 *$ & $4.5^{*}$ & $2.5^{*}$ & n.d. & 1.9 & n.d. & 0.9 \\
\hline $22: 1 \omega 9$ & 1.7 & 0.5 & 0.5 & 0.5 & 0.6 & n.d. & n.d. & 0.5 \\
\hline $24: 1 \omega 9$ & n.d. & n.d. & n.d. & n.d. & n.d. & 2.6 & n.d. & 1.8 \\
\hline $18: 2 \omega 6^{\mathrm{b}}$ & $2.7 *$ & $1.4^{*}$ & $(0.8)$ & $(0.3)$ & 2.5 & n.d. & n.d. & n.d. \\
\hline $19: 2 \omega 6$ & n.d. & 0.3 & n.d. & 0.1 & n.d. & n.d. & n.d. & n.d. \\
\hline $20: 2 \omega 6$ & $6.1^{*}$ & $0.8^{* *}$ & $0.7 * *$ & $0.8^{* *}$ & $2.9^{*}$ & n.d. & $0.2 * *$ & $0.8 * *$ \\
\hline $22: 2 \omega 6$ & 1.9 & n.d. & n.d. & n.d. & 0.4 & n.d. & n.d. & n.d. \\
\hline $18: 3 \omega 3^{c}$ & $2.2^{*}$ & $0.9^{* *}$ & n.d. & $0.3^{* *}$ & $2.4^{*}$ & $18.6^{* *}$ & $18.5^{* *}$ & $11.5^{*, * *}$ \\
\hline $20: 3 \omega 3$ & $3.0^{*}$ & $0.4^{* *}$ & n.d. & $0.5^{* *}$ & 2.0 & n.d. & n.d. & 0.3 \\
\hline $20: 3 \omega 6^{b}$ & $2.0^{*}$ & $1.5^{*}$ & $0.6^{*}$ & $(0.2)$ & 0.8 & n.d. & n.d. & 0.2 \\
\hline $22: 3 \omega 6$ & n.d. & 1.0 & 0.5 & 0.2 & 3.6 & n.d. & n.d. & n.d. \\
\hline $18: 4 \omega 3$ & $2.2 *$ & $11.6^{* *}$ & $14.8^{* *}$ & $13.6^{* *}$ & 1.4 & n.d. & n.d. & 1.3 \\
\hline $20: 4 \omega 3$ & $1.7^{*}$ & $10.7 * *$ & $14.6 * *$ & $11.5^{* *}$ & $1.3^{*}$ & $6.4^{* *}$ & n.d. & $1.1^{*}$ \\
\hline $20: 4 \omega 6$ & n.d. & 0.4 & n.d. & 0.1 & n.d. & n.d. & n.d. & 0.4 \\
\hline $22: 4 \omega 6$ & 0.6 & n.d. & n.d. & n.d. & n.d. & n.d. & n.d. & n.d. \\
\hline $20: 5 \omega 3$ & 1.1 & n.d. & n.d. & n.d. & 1.4 & n.d. & n.d. & n.d. \\
\hline $21: 5 \omega 2$ & n.d. & n.d. & n.d. & n.d. & n.d. & n.d. & n.d. & 1.2 \\
\hline $22: 5 \omega 3$ & $3.4 *$ & $6.5^{*}$ & $11.7^{*}$ & $7.6^{*}$ & 5.0 & 4.6 & n.d. & n.d. \\
\hline $22: 6 \omega 3$ & $5.2 *$ & $1.2 *$ & $1.8^{*}$ & $4.1^{*}$ & $3.9^{*}$ & $3.0^{*}$ & $3.6^{*}$ & $5.0 *$ \\
\hline
\end{tabular}

${ }^{\mathrm{a}, \mathrm{b}, \mathrm{c}}$ See the footnotes of Table 1 and Table 2.

tions in specific fatty acid compositions during lamprey metamorphosis. This alteration may result from any combination of the following factors: (1) life history pattern (benthic vs. pelagic, freshwater vs. seawater, thermal adaptation, etc.); (2) development (tissue reorganization); (3) the nature of lipid class; (4) nutritional status (feeding vs. fasting); and (5) environmental cues (e.g. temperature, salinity).

In this study, palmitic acid (16:0) and stearic acid (18:0), and to a lesser extent, 17:0, are generally predominant constituents in each lipid class before and during metamorphosis of sea lamprey with the exception of the renal TG class (14:0 was most abundant, 16:1 also included) and CE class (14:0, 17:0, 18:0 and 18:1), hepatic MG class $(18: 4 \omega 3,20: 4 \omega 3,22: 5 \omega 6)$, and intestinal CE class $(17: 0,18: 1,18: 1,19: 0,24: 0)$. Palmitic acid and 18:0 (to a lesser extent, 17:0) generally were the predominant saturated fatty acids; $16: 1,18: 1$ and 20:1 accounted for the majority of monoenes; 18:2 and 20:2 accounted for majority of dienes; 
Table 6

Fatty acid composition (mol.\%) of diacylglycerol in the liver and intestine of lamprey, P. marinus, during metamorphosis ${ }^{\mathrm{a}}$

\begin{tabular}{|c|c|c|c|}
\hline \multirow{2}{*}{$\begin{array}{l}\text { Fatty } \\
\text { acids }\end{array}$} & \multicolumn{3}{|c|}{ Intestine } \\
\hline & 3 & 5 & 7 \\
\hline$n-14: 0^{\mathrm{b}}$ & n.d. & $0.5^{*}$ & $1.0^{*}$ \\
\hline$n-15: 0^{\mathrm{b}}$ & $(0.1)$ & $1.2^{*}$ & $2.4^{*}$ \\
\hline$n-16: 0^{\mathrm{b}}$ & $22.2 *$ & $36.5^{*}$ & $29.5^{*}$ \\
\hline$n-17: 0^{\mathrm{b}}$ & $3.4^{*}$ & $5.2 * *$ & $5.6^{* *}$ \\
\hline$n-18: 0^{\mathrm{b}}$ & $23.6^{*}$ & $21.2^{*}$ & $24.3^{*}$ \\
\hline 19:0 & n.d. & n.d. & 0.5 \\
\hline 20:0 & n.d. & $1.1^{*}$ & $0.9 *$ \\
\hline $21: 0$ & $(0.7)$ & $2.0^{*}$ & $1.6^{*}$ \\
\hline $22: 0$ & $8.1^{*}$ & $6.6^{*}$ & $5.8^{*}$ \\
\hline $24: 0$ & $5.4^{*}$ & $2.5^{*}$ & $3.4^{*}$ \\
\hline $15: 1 \omega 5$ & $(1.0)$ & $2.4^{*}$ & $1.3 *$ \\
\hline $16: 1 \omega 7^{b}$ & n.d. & n.d. & 1.5 \\
\hline $18: 1 \omega 9^{b}$ & n.d. & $1.2^{*}$ & $3.1^{*}$ \\
\hline $20: 1 \omega 9^{b}$ & n.d. & $(0.3)$ & $(0.3)$ \\
\hline $18: 2 \omega 6^{\mathrm{b}}$ & n.d. & n.d. & 0.8 \\
\hline $20: 2 \omega 6$ & n.d. & $0.4^{*}$ & $0.9^{*}$ \\
\hline $18: 3 \omega 3^{c}$ & $10.7 *$ & $8.4^{*}$ & $7.7 *$ \\
\hline $20: 3 \omega 3$ & $(0.2)$ & 0.4 & $(0.3)$ \\
\hline $20: 3 \omega 6^{b}$ & n.d. & $0.6^{*}$ & $0.6^{*}$ \\
\hline $18: 4 \omega 3$ & $(8.2)$ & (1.9) & (1.9) \\
\hline $20: 4 \omega 3$ & 7.4 & $(1.7)$ & $(1.6)$ \\
\hline $20: 4 \omega 6$ & n.d. & $(0.4)$ & n.d. \\
\hline $20: 5 \omega 3$ & n.d. & n.d. & n.d. \\
\hline $22: 5 \omega 3^{b}$ & $(4.6)$ & n.d. & $(2.4)$ \\
\hline $22: 6 \omega 3$ & $4.5^{*}$ & $5.5^{*}$ & $2.6^{*}$ \\
\hline
\end{tabular}

${ }^{\mathrm{a}, \mathrm{b}, \mathrm{c}} \mathrm{S}$ See the footnotes of Table 1 and Table 2 .

18:3, 18:4 and 20:4 accounted for the majority of polyenes ( $\geqq 3$ double bonds). Alterations in these predominant fatty acids during lamprey metamorphosis suggest their dependence on tissue, lipid class and developmental status.

The present report indicated that alterations in the fatty acid composition during lamprey metamorphosis depend on tissues. This conclusion is supported by several lines of evidence. First, FA of the TG class from sea lamprey kidney has a lower USFA/SFA ratio, a lower unsaturation index and a shorter mean chain length of TG class than those of the liver and intestine, reflecting that TG fatty acids in the latter two organs are more desaturated and elongated. Shorter MCL of renal TG fatty acids primarily resulted from a large amount of 12:0, 14:0, 16:1 and partially from 15:0. In contrast, FA of the PL class from the kidney has a higher USFA/SFA ratio, USI and MCL of
PL class than those of the liver and intestine. This is attributable to greater proportion of PUFA in kidney PL. Second, FA of the CE class from liver has a higher USI than those of intestine. This observation is due to greater proportions of $\mathrm{ME}$ and PUFA (particularly $\omega 6$ family). In addition, hepatic MG class displayed a greater proportion of BCSFA, but a lower proportion of SFA than FA from the intestine MG class. This study is the first to report fatty acid composition in the lamprey kidney and intestine. Alteration patterns in fatty acid composition of the liver, gonad and muscle have been reported in several species of lamprey (Fellows and Mclean, 1982; Bird and Potter, 1983; Bird et al., 1993; Whyte et al., 1993).

The present report indicates that alterations in the lamprey fatty acid composition may be associated with developmental tissue reorganization. This conclusion is also supported by several lines of evidence. First, increased PUFA of kidney TG fatty acids from larva to stage 3 is consistent with the reported degenerations of larval kidney (Youson, 1980), an organ which possessed large amounts of lipid (Youson et al., 1979; Kao et al., 1997a). In contrast, increased unsaturation (due to more PUFA) and great abundance of BCSFA in the renal PL fatty acids from larva to stage 5 observed in this study parallels the formation of a new, definite kidney (Youson, 1980). Perhaps increased amounts of PUFA and BCSFA contribute to the membrane fluidity of the developing nephron during late metamorphosis since they have a low melting point (Christie, 1987). Second, there was a tendency to increase saturation in liver TG and PL fatty acids, but to increase unsaturation in liver CE, FA and MG fatty acids from larva to stage 7 . This observation is consistent with the degeneration of the bile duct system (Youson, 1985). Increased unsaturation of hepatic fatty acids from larva to stage 7 , along with the retention of TG fatty acid unsaturation, may be associated with increased energy utilization over this non-trophic phase. Third, a two-phase-like pattern of changes in SFA and USFA of intestinal fatty acid composition attended transformation of the intestine (Youson and Horbert, 1982; Youson, 1985) and a two-phase metabolic pattern of this tissue (Kao et al., 1997a,b). Finally, fatty acids in the liver FA and MG classes were generally more unsaturated during metamorphosis, while intestinal FA and MG classes tended to be more saturated. 
Alterations in tissue fatty acid composition of sea lamprey accompanying their metamorphosis from freshwater ammocoetes to freshwater macropthalmia reported here are unlike those associated with the smoltification of salmonid fishes which transform from freshwater parr to freshwater smolt (Sheridan et al., 1985). For example, fluc-

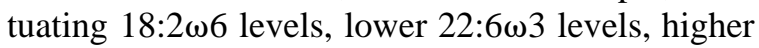
BCSFA levels and undetectable 20:5 03 occurred in the macropthalmia liver. These differences between lamprey and trout may be attributable to the distinct dietary source and physiological status of the animals. Larval sea lampreys are the filterfeeding detritivores (Moore and Mallatt, 1980) and the transforming lampreys are spontaneously starved during metamorphosis (Youson, 1980), whereas parr and smolts both are carnivores and feed during smoltification (Hoar, 1988). This interpretation is supported by other investigations as reported in the different periods of the life history of several lampreys (Bird and Potter, 1983; Bird et al., 1993; Whyte et al., 1993). These studies indicated that freshwater upstream migrants and adults of anadromous parasitic lampreys, which have a feeding juvenile phase on freshwater or seawater teleost fish flesh, showed considerable amount of 22:6 $\omega 3$ and the marine type of teleost fatty acids, such as higher $\omega 3 / \omega 6$ PUFA ratio. In anurans, alterations in hepatic fatty acid compositions also have been reported to accompany the metamorphosis of aqueous herbivore tadpoles to terrestrial carnivore frog (Hoch, 1988). Decreased monoenes and increased polyunsaturated fatty acids were observed during amphibian metamorphosis (Hoch, 1988).

Alterations in the FA composition of metamorphosing lampreys may result from salinity, nutrition and starvation. First, kidney TG and PL fatty acids and intestine PL fatty acids tended to be more polyunsaturated as metamorphosis proceeded and liver TG and PL and intestine TG fatty acids generally became less polyunsaturated. Increased PUFA in kidney TG and PL and intestine PL may reflect an osmoregulatory pre-adaptation since fatty acids of seawater-adapted fish tend to be more polyunsaturated than their freshwater counterparts (Henderson and Tocher, 1987), since lamprey do display an increase in serum osmolarity (Mathers and Beamish, 1974), and since both tissues play an important role in the osmoregulation (Youson, 1980, 1985). Differences in the fatty acid composition of freshwater and marine teleost fishes have been extensively reported (Gruger et al., 1964; Ackman, 1967; Stansby, 1967; Henderson and Tocher, 1987).

Second, the presence of high levels of BCSFA (mainly iso- and anteiso-methyl) and ONFA (15:0, 17:0 and 19:0) in the fatty acids of larval liver, kidney and intestine of this study indicates a significant role of benthic detritus, sediment and bacteria in the larval lamprey nutrition, since BCSFA and ONFA are the major fatty acids in bacteria (Christie, 1987; Gurr and Harwood, 1991) and since lampreys did filter-feed on sedimental detritius (Moore and Beamish, 1973; Moore and Mallatt, 1980).

In addition, the presence of high levels of 16:1 (particularly $\omega 9$ besides $\omega 7$ and $\omega 11$ ) and generally higher levels of $\mathrm{C} 18$ than C20 or C22 PUFA in the TG and PL classes of larval kidney, liver and intestine also indicates that fatty acids from freshwater algae (e.g. diatoms) can form the diet of larval sea lamprey, P. marinus. This is supported by evidence that freshwater algae generally contain substantial amounts of 16:1 and higher levels of C18 than C20 or C22 PUFA (Henderson and Tocher, 1987), and because larval sea lamprey selectively favor specific genera of diatoms, such as Navicula, Synedra and Gomphonema (Manion, 1967; Moore and Beamish, 1973). These observations in benthic food preferences of larval $P$. marinus is consistent with that reported in $G$. australis (Bird and Potter, 1983). Finally, metamorphosing sea lamprey (stages 3,5 and 7) used in this study are spontaneously starved (Youson, 1980) as compared with the larval animal (Moore and Mallatt, 1980). This observation may be reflected by a general decrease in dienes of liver and intestine lipid classes and by the mobilization of BCSFA, ONFA, and 16:1 from intestinal lipid classes.

On the other hand, preferential mobilization of SFA from renal TG primarily resulted from a medium chain (less than C16) of fatty acids. This observation confirmed the study by Bird et al. (1993) that non-parasitic adult L. planeri relied on the larval diet and preferred to use shorter chain length FA in muscle TG. The observations in liver TG observed in naturally starved lamprey, P. marinus, are somewhat different from that reported in juvenile and adult lamprey (Whyte et al., 1993), trout (Jezierska et al., 1982) and sea bass (Delgado et al., 1994). This difference possibly suggests the existence of species specificity. 
Alterations in fatty acid composition of sea lamprey tissues accompany its metamorphosis. These changes in fatty acid compositions would contribute to energy (e.g. TG) and membrane (e.g. $\mathrm{PL}$ and $\mathrm{CE}$ ) uses at a time when there is transformation and regression of the larval structures and development of new tissues and organs during metamorphosis of sea lamprey. However, further studies on the effects of physiological factors (e.g. hormones) and environmental cues (e.g. temperature) on fatty acid compositions are needed to elucidate the developmental regulation of lipid metabolism during lamprey metamorphosis.

\section{Acknowledgements}

We are grateful to the United States Department of Agriculture (USDA), Northern Crop Science Laboratory, Fargo, North Dakota, USA for the use of GC and GC-Mass Spectrometer. This work was supported by grants from the National Science Foundation, USA (IBN 9406707) to M.A.S. and from Great Lakes Fishery Commission to J.H.Y. and from the National Science Council, Taiwan (NSC 89-2320-B-008-004) and NSC 90-2311-B008-002) to Y.-H.K.

\section{References}

Ackman, R.G., 1967. Characteristics of the fatty acid composition and biochemistry of some fresh-water fish oils and lipids in comparison with marine oils and lipids. Comp. Biochem. Physiol. 22, 907-922.

Ackman, R.G., Burgher, R.D., 1964. Cod liver oil: component fatty acids as determined by gas-liquid chromatography. J. Fish. Res. Bd. Can. 21, 319-326.

Andersson, B.A., Holman, R.T., 1974. Pyrrolidides for mass spectrometric determination of the position of the double bond in monounsaturated fatty acids. Lipids 9, 185-190.

Beamish, F.W.H., 1980. Biology of the North American anadromous sea lamprey, Petromyzon marinus. Can. J. Fish. Aquat. Sci. 37, 1924-1943.

Bird, D.J., Potter, I.C., 1983. Changes in the fatty acid composition of triacylglycerols and phospholipids during the life cycle of the lamprey Geotria australis Gray. Comp. Biochem. Physiol. B 75, 31-41.

Bird, D.J., Ellis, D.J., Potter, I.C., 1993. Comparisons between the fatty acid compositions of the muscle and ovary of the nonparasitic lamprey Lampetra planeri (Bloch) and their counterparts in the anadromous and parasitic L. fluviatilis (L.). Comp. Biochem. Physiol. B 105, 327-332.

Christie, W.W., 1987. HPLC and Lipids, A Practical Guide. Pergamon Press, New York.

Delgado, A., Estevez, A., Hortelano, P., Alejandre, M.J., 1994. Analysis of fatty acids from different lipids in liver and muscle of sea bass (Dicentrarchus labrax L.). Influence of temperature and fasting. Comp. Biochem. Physiol. A 108, 673-680.

Fellows, F.C.I., Mclean, R.M., 1982. A study of the plasma lipoproteins and the tissue lipids of the migrating lamprey, Mordacia mordax. Lipids 17, 741-747.

Freeman, C.P., West, D., 1966. Complete separation of lipid classes on a single thin-layer plate. J. Lipid Res. 7, 324327.

Gruger, E.H., Nelson, R.W., Stansby, M.E., 1964. Fatty acid composition of oils from twenty-one species of marine fish, freshwater fish, and shellfish. J. Am. Oil Chem. Soc. 41, 662-670.

Gurr, M.I., Harwood, J.L., fourth ed, 1991. Lipid Biochemistry: An Introduction. Chapman and Hall, London.

Hardisty, M.W., 1979. The Biology of the Cyclostomes. Chapman and Hall, London.

Henderson, R.J., Tocher, D.R., 1987. The lipid composition and biochemistry of freshwater fish. Prog. Lipid Res. 26, 281-347.

Hoar, W.S., 1988. The physiology of smolting salmonids. In: Hoar, W.S., Randall, D.J. (Eds.), Fish Physiology, Vol. XI. Academic Press, New York, pp. 275-344.

Hoch, F.L., 1988. Lipids and thyroid hormones. Prog. Lipid Res. 27, 199-270.

Jezierska, B., Hazel, J.R., Gerking, S.D., 1982. Lipid mobilization during starvation in the rainbow trout, Salmo gairdneri Richardson, with attention to fatty acids. J. Fish Biol. 21, 681-692.

Kao, Y.H., Youson, J.H., Sheridan, M.A., 1997a. Differences in the total lipid and lipid class composition of larvae and metamorphosing sea lampreys, Petromyzon marinus, during metamorphosis. Fish Physiol. Biochem. 16, 281-290.

Kao, Y.H., Youson, J.H., Holmes, J.A., Sheridan, M.A., 1997 b. Changes in lipolysis and lipogenesis in selected tissues of the landlocked lamprey, Petromyzon marinus, during metamorphosis. J. Exp. Zool. 277, 301-312.

LeBlanc, P.J., Gillis, T.E., Gerrits, M.F., Ballantyne, J.S., 1995. Metabolic organization of liver and somatic muscle of landlocked sea lamprey, Petromyzon marinus, during the spawning migration. Can. J. Zool. 73, 916-923.

Lowe, D.R., Beamish, F.W.H., Potter, I.C., 1973. Changes in the proximate body composition of the landlocked sea lamprey Petromyzon marinus (L.) during larval life and metamorphosis. J. Fish Biol. 5, 673-682.

Manion, P.J., 1967. Diatoms as food of larval sea lampreys in a small tributary of northern Lake Michigan. Trans. Am. Fish. Soc. 96, 224-226.

Mathers, J.S., Beamish, F.W.H., 1974. Changes in serum osmotic and ionic concentration in landlocked Petromyzon marinus. Comp. Biochem. Physiol. 49A, 677-688.

Moore, J.W., Beamish, F.W.H., 1973. Food of larval sea lamprey (Petromyzon marinus) and American brook lamprey (Lampetra lamottei). J. Fish. Res. Board Can. 30, 715.

Moore, J.W., Mallatt, J.M., 1980. Feeding of larval lamprey. Can. J. Fish. Aquat. Sci. 37, 1658-1664.

Morrison, W.R., Smith, L.M., 1964. Preparation of fatty acid methyl esters and diamethylacetals from lipids with boron fluoride-methanol. J. Lipid Res. 5, 600-608.

O'Boyle, R.N., Beamish, F.W.H., 1977. Growth and intermediary metabolism of larval and metamorphosing stages of 
the landlocked sea lamprey, Petromyzon marinus L. Env. Biol. Fish. 2, 103-120.

Potter, I.C., Wright, G.M., Youson, J.H., 1978. Metamorphosis in the anadromous sea lamprey, Petromyzon marinus L. Can. J. Zool. 56, 561-570.

Sheridan, M.A., 1994. Regulation of lipid metabolism in poikilothermic vertebrates. Comp. Biochem. Physiol. B 107, 495-508.

Sheridan, M.A., Allen, W.V., Kerstetter, T.H., 1985. Seasonal variations in the lipid composition of steelhead trout, Salmo gairdnerii Richardson, associated with parr-smolt transformation. J. Fish Biol. 23, 125-134.

Stansby, M.E., 1967. Fatty acid patterns in marine, freshwater and anadromous fish. J. Am. Oil Chem. Soc. 44, 64.

Whyte, J.N.C., Beamish, R.J., Ginther, N.G., Neville, C.E., 1993. Nutritional condition of the Pacific lamprey (Lampetra tridentata) deprived of food for periods of up to two years. Can. J. Fish. Aquat. Sci. 50, 591-599.

Youson, J.H., 1980. Morphology and Physiology of lamprey metamorphosis. Can. J. Fish. Aquat. Sci. 37, 1687-1710.
Youson, J.H., 1985. Organ development and specialization in lamprey species. In: Gorbman, A., Dodd, J.M., Olsson, R. (Eds.), Evolutionary Biology of Primitive Fishes, Plenum Press, New York, pp. 141-164.

Youson, J.H., Horbert, W.R., 1982. Transformation of the intestinal epithelium of the larval anadromous sea lamprey, Petromyzon marinus L., during metamorphosis. J. Morphol. 171, 89-117.

Youson, J.H., Potter, I.C., 1979. A description of the stages in the metamorphosis of the anadromous sea lamprey, Petromyzon marinus, L. Can. J. Zool. 57, 1808-1817.

Youson, J.H., Lee, J., Potter, I.C., 1979. The distribution of fat in larval, metamorphosing and young adult anadromous sea lamprey, Petromyzon marinus L. Can. J. Zool. 57, 237246.

Youson, J.H., Holmes, J.A., Guchardi, J.A., et al., 1993. Importance of condition factor and the influence of water temperature and photoperiod on metamorphosis of sea lamprey, Petromyzon marinus. Can. J. Fish. Aquat. Sci. 50, $2448-2456$. 